\title{
IMPLEMENTACIÓN DEL CONVENIO DE ESTAMBUL EN LA REFUNDICIÓN DEL REGLAMENTO BRUSELAS II BIS Y SU REPERCUSIÓN EN LA SUSTRACCIÓN INTERNACIONAL DE MENORES
}

\author{
THE IMPLEMENTATION OF THE ISTANBUL CONVENTION \\ IN THE RECASTING OF THE BRUSSELS II BIS REGULATION \\ AND ITS IMPACT ON THE INTERNATIONAL CHILD \\ ABDUCTION
}

\author{
CARMen Ruiz SutiL* \\ Profesora titular de Derecho internacional privado \\ Universidad de Granada \\ ORCID: 0000-0001-5063-1845
}

Recibido: 14.07.2018 / Aceptado: 30.07.2018

DOI: https://doi.org/10.20318/cdt.2018.4392

\begin{abstract}
Resumen: Los instrumentos internacionales en materia de sustracción ilícita de menores no ofrecen respuestas satisfactorias a las situaciones motivadas por la violencia de género, lo que pone de relieve el fracaso de los mecanismos articulados para ello. En estos momentos, se está revisando en la UE el Texto de Refundición del Reglamento (CE) número 2201/2003, donde se presta una especial atención a la cuestión de la sustracción de menores por uno de sus progenitores. Por otra parte, a pesar de la profusión de normativas y medidas existentes para la lucha contra la violencia de género y la adhesión de la Unión al Convenio de Estambul para prevenir y combatir la violencia contra las mujeres y la violencia de género, no se está llevando a cabo a cabo la implementación ansiada en los instrumentos internacionales concernientes a la sustracción internacional de menores. Particularmente, en situaciones intraeuropeas, analizaremos el "retorno seguro" de las y los menores sustraídos expuestos a un grave riesgo en contextos de violencia de género/doméstica, regla general impuesta en el actual art. 11.4 del Reglamento Bruselas II bis. En este trabajo se propondrá soluciones para una restitución con medidas de seguridad a la luz del ordenamiento jurídico español, teniendo presente la existencia de instrumentos europeos de reconocimiento mutuo de resoluciones penales en la Unión Europea, entre los que se encuentra la Orden Europea de Protección.
\end{abstract}

Palabras clave: menores expuestos a la violencia de género/doméstica, sustracción internacional de menores, Convenio de Estambul, Texto de Refundición del Reglamento Bruselas II bis, retorno seguro y la Orden Europea de Protección.

\footnotetext{
Abstract: International instruments with regards to international child abduction do not present satisfactory answers to the gender based violence situations. This highlights the failure of its mechanisms. The Recasting Text of the Regulation (CE) 2201/2003 is being currently revised in the EU, and a special attention is drawn to the issues related to child abduction by one of the parents. Moreover, despite the

*(ruizsuti@ugr.es). Este trabajo se enmarca dentro del Proyecto de Investigación I+D+i que lleva como título "Movilidad internacional de personas: el impacto jurídico-social en España y en la UE de la adquisición de la nacionalidad española por la población inmigrante", con código DER2016-75573-R
} 
myriad of rules and measures existing in the field of fight against gender based violence and despite the adhesion of the EU to the Istanbul Convention to prevent and fight violence against women, the implementation coveted for in the international instruments on international child abduction is not achieved. We will analyze, particularly in the intra-European situations, the "safe return" of children exposed to high risks in contexts of domestic violence/Gender based violence (GBV), as a general rule established by the current article 11.4 of the Brussels II Bis Regulation. In this paper, we will propose solutions to a return accompanied by security measures in light of the Spanish Legal system, taking into account the existence of European instruments of mutual recognition of penal decisions in the EU such as the European Protection Order.

Keywords: children exposed to gender based violence/domestic violence, international child abduction, Istanbul Convention; Text of Recasting the Brussels II bis Regulation, safe return and the European Protection Order.

Sumario: I. Introducción; II. Precisa implementación del Convenio de Estambul en la normativa sobre sustracción internacional de menores: 1. Menores expuestos a la violencia de género en el Convenio de Estambul y su repercusión en los textos europeos sobre sustracción internacional; 2. El impacto del Convenio de Estambul en la legislación española sobre sustracción internacional de menores. III. Interconexión de la violencia de género y el grave riesgo para la no restitución en situaciones europeas: 1. El grave riesgo de las y los menores en escenarios de violencia de género; 2. Aspectos relevantes del Texto de Refundición en el tratamiento de la sustracción internacional de menores y la violencia de género; IV. El retorno seguro y la violencia de género en el contexto europeo: 1. La "restitución segura" ante la violencia de género; 2. La Orden Europea de Protección para un retorno seguro de las víctimas y de los hijos e hijas sustraídos cuando concurre violencia de género; V. Conclusiones.

\section{Introducción}

1. En la Unión Europea (en adelante UE) se viene comprobando que la naturaleza transnacional de los procedimientos de sustracción ilícita de menores y la importancia del factor tiempo, junto con el delicado tema de la violencia de género y su repercusión en los hijos e hijas, dificultan soluciones que garanticen el verdadero interés superior de las y los niños sustraídos en todos los casos. El aumento considerable de situaciones en las que las mujeres víctimas de la violencia machista ejercida por su pareja o ex pareja se ven obligadas a huir con sus hijos e hijas, seguramente movidas por el miedo y por la falta o desconocimiento de mecanismos que garanticen el auxilio en el país de su residencia habitual ${ }^{1}$, nos indica que los sistemas diseñados para combatir la sustracción internacional y la lucha contra la violencia de género están fracasando.

2. Actualmente, las instituciones de la UE, en el marco del procedimiento legislativo especial con base jurídica del art. 81.3 del TFUE², vienen revisando la propuesta de modificación del Reglamen-

\footnotetext{
1 En concreto, los casos de traslado ilícito del menor llevados a cabo por el titular del derecho de custodia por causas de violencia de género van en aumento, tal y como ya se ha expuesto por M. KAYE, "The Hague Convention and the flight from domestic violence: how women and children are being returned by coach and four", International Journal of Law, Policy and the Family, 1999, 13, pp. 191-212; M. H. WeINER, International child abduction and the escape from domestic violence. Fordham Law Review, 2000, 69, pp. 593-706. También en H. BALE, "Taking Flight-Domestic Violence and Child Abduction", Current Legal Problems, Volume 70, Issue 1, 1 December 2017, Pages 3-16, https://doi.org/10.1093/clp/cux001_(consultado 20 de junio de 2018), donde se explica que el perfíl de la persona que sustráe a los y las menores ha ido cambiando. Sobre esta metamorfosis sociológica véase el Consejo de Europa en Repport "Cross-border parental responsibility conflicts", Committee on Social Affairs, Health and Sustainable Development, Doc. 14435, de 30 de octubre de 2017; P. JimÉnEz BlanCo, Litigios sobre la custodia y sustracción internacional de menores, Madrid, Marcial Pons, 2008, pp. 12-16.

2 Art. 81.3 TFUE, "No obstante, lo dispuesto en el apartado 2 de este precepto, las medidas relativas al Derecho de familia con repercusión transfronteriza se establecerán por el Consejo, con arreglo a un procedimiento legislativo especial. El Consejo se pronunciará por unanimidad, previa consulta al Parlamento Europeo. El Consejo, a propuesta de la Comisión, podrá adoptar una decisión que determine los aspectos del Derecho de familia con repercusión transfronteriza que puedan ser objeto de actos adoptados mediante el procedimiento legislativo ordinario....".
} 
to (CE) número 2201/2003 relativo a la competencia, el reconocimiento y la ejecución de resoluciones en materia matrimonial y de responsabilidad parental, y sobre la sustracción internacional de menores (refundición) ${ }^{3}$. Este Texto de Refundición presta atención a determinados aspectos de los procedimientos relacionados con menores, en particular, los relacionados con la sustracción internacional. Ello nos obliga a examinar si las modificaciones sustanciales presentadas van a contribuir a reforzar la seguridad jurídica y garantizar el interés de la o del menor, incluidos los de naturaleza tan dolorosa, como cuando concurre violencia de género o doméstica.

3. Existen investigaciones que verifican que la "no devolución" del hijo o de la hija al país de su residencia habitual solo prospera cuando el maltrato físico se ejerce directamente sobre la persona menor, pero no si la violencia es perpetrada exclusivamente sobre la madre, aunque aquellos sean testigos presenciales ${ }^{4}$. Este tipo de experiencias ponen en jaque el funcionamiento actual del principal instrumento internacional en materia de sustracción internacional de menores: el Convenio de La Haya de 25 de octubre de 1980, sobre aspectos civiles de la sustracción internacional de menores ${ }^{5}$ (en adelante CLH 1980). En ocasiones, dicha convención se convierte en arma legal para que el cónyuge maltratador ejerza mayor control sobre la víctima. En retenciones o desplazamientos ilícitos de menores entre países europeos, el Reglamento (CE) $n^{\circ}$ 2201/2003, del Consejo de 27 de noviembre de 2003, relativo a la competencia, el reconocimiento y la ejecución de resoluciones judiciales en materia matrimonial y de responsabilidad parental (en adelante RBr. II bis), es el que otorga soluciones encaminadas a priorizar el regreso del o de la menor al país de su residencia habitual, garantizado el principio de confianza entre Estados miembros.

4. Además de estos instrumentos, algunos países de la UE, entre ellos España, se encuentran vinculados al Convenio de Estambul sobre prevención y lucha contra la violencia contra las mujeres y la violencia doméstica de 11 de mayo de $2011^{6}$ (en adelante Convenio de Estambul), nacido al amparo del Consejo de Europa, y que también ha sido firmado por la Unión ${ }^{7}$, aunque falta su ratificación. Lo relevante es que obliga a los actuales Estados contratantes del Convenio de Estambul a la protección y defensa de las y los hijos de las víctimas de la violencia de género a través de la adopción de medidas civiles (art. 31), sin bien, ninguna de sus disposiciones quedan vinculadas a los instrumentos internacionales en materia de responsabilidad parental y de sustracción internacional de menores.

5. De ahí que con el presente estudio se pretenda determinar hasta qué punto es necesario interconectar las soluciones establecidas en el Convenio de Estambul y las instauradas en la normativa internacional de sustracción internacional de menores con el objetivo de proporcionar respuestas más satisfactorias y garantistas cuando concurran situaciones de violencia de género. Y es que se corre el riesgo de dar lugar a escenarios materialmente injustos si, en la aplicación de dichos textos internacionales, no se atiende ni al contexto ni a la realidad que comporta dicha violencia estructural.

\footnotetext{
${ }^{3}$ Véase el documento $\operatorname{COM}(2016) 411$ fina, Propuesta de Reglamento del Consejo relativo a la competencia, el reconocimiento y la ejecución de resoluciones en materia matrimonial y de responsabilidad parental, y sobre la sustracción internacional de menores (refundición).

4 Vid. T. Lindhorst and J. L. EdLeson, Battered women, their children, and international law - The unintended consequences of the Hague Child Abduction Convention. 2012, Amherst, NH: Northeastern University Press. Un estudio sobre las sustracciones parentales en Estados Unidos demuestra que en al menos la mitad de los casos de secuestro parental, la violencia doméstica tiene una presencia relevante, en J. Chiancone, L. Girdner \& P. Hoff, "Issues in resolving cases of international child abduction by parents", Juvenile Justice Bulletin, 2001, en https://www.ncjrs.gov/pdffiles1/ojjdp/190105.pd (consultado 2 de junio de 2018). Vid. S. Yamaguchi and T. Lindhorst, "Domestic Violence and the Implementation of the Hague Convention on the Civil Aspects of International Child Abduction: Japan and U.S. Policy", 2016, Journal of International Women's Studies, vol. 17, Issue 4, pp. 15-30, en esp. pp. 18 y 19. http://vc.bridgew.edu/cgi/viewcontent.cgi?article=1883\&context=jiws (consultado el 19 de mayo de 2018).

5 BOE núm. 202, de 24 de agosto de 1980.

6 Para España, BOE núm. 137, de 6 de junio de 2014. Véase https://www.coe.int/en/web/conventions/full-list/-/conventions/treaty/210/signatures?desktop=true

${ }^{7}$ En Resolución del Parlamento Europeo, de 12 de septiembre de 2017, sobre la propuesta de Decisión del Consejo relativa a la celebración, por la Unión Europea, del Convenio del Consejo de Europa sobre prevención y lucha contra la violencia contra las mujeres y la violencia doméstica (COM(2016)0109 - 2016/0062(NLE).
} 
6. Por otra parte, en este trabajo nos planteamos si la Orden Europea de Protección (en adelante OEP), como mecanismo de reconocimiento mutuo de decisiones penales en la UE para proteger a la víctima de violencia de género y a sus hijos o hijas, resulta un recurso adecuado para un retorno seguro al país de la residencia habitual cuando el motivo de la huida de dicho lugar fue la violencia de género. En aras a la aplicación coherente de la legislación de la Unión, vincularemos las diversas normativas existentes, tanto penales como civiles, que afecten al interés de la o del menor sustraído en escenarios de violencia de género o doméstica.

\section{Precisa implementación del Convenio de Estambul en la normativa sobre sustracción interna- cional de menores}

\section{Menores expuestos a la violencia de género en el Convenio de Estambul y su repercusión en los textos europeos sobre sustracción internacional}

7. En el ámbito internacional, y desde la óptica de los derechos humanos ${ }^{8}$, existe un marco jurídico tendente a proteger a la mujer víctima de la violencia en el seno de la pareja o de la familia. Esta normativa es el resultado del empeño de los organismos internacionales creados el pasado siglo $\mathrm{XX}^{9}$ para plasmar una realidad acuciante y arraigada en un contexto general de discriminación sistémica contra la mujer y otras formas de subordinación ${ }^{10}$. Para combatirla, se proclama una vida sin violencia de género, siendo un auténtico derecho subjetivo, donde su incumplimiento debe generar consecuencias jurídicas en los Estados ${ }^{11}$.

8. La Convención de Naciones Unidas sobre la eliminación de todas las formas de discriminación de la mujer de $1979^{12} \mathrm{y}$, en particular, la Cuarta conferencia mundial sobre la mujer, celebrada en Beijing, del 4 al 15 de septiembre de $1995^{13}$, han supuesto el reconocimiento y conciencia a nivel internacional sobre el significado de la violencia de género, especialmente la que se manifiesta en el ámbito familiar como estrategia de dominación del hombre hacia la mujer y su estrecha vinculación con la discriminación de sexo. Esta violencia no sólo afecta mundialmente a un gran número de mujeres, sino que también es soportada directa o indirectamente por sus hijos o hijas, tal y como recogen en las recomendaciones y decisiones del Comité para la eliminación de la discriminación contra la mujer de Naciones Unidas (CEDAW).

9. En esta dirección, la Convención de las Naciones Unidas de los Derechos del Niño de 20 de noviembre de $1989^{14}$ (en adelante CNUDN) y sus Protocolos facultativos han expresado su preocupación por el impacto de las distintas formas de violencia, especialmente la de género y su exposición, al repercutir en su desarrollo integral ${ }^{15}$. Esta inquietud se ha visto reflejada en el art. 19 CNUDN, al afirmar

8 Vid. J. Ma. Gil Ruiz, "Derechos humanos, violencia de género y maltrato jurídico. Bases para entender el tratamiento integral de la Violencia de Género", Anuario de Filosofía del Derecho, 2005, núm., 22, pp. 53-82. Véase el manual de Naciones Unidas, Los derechos de la mujeres son derechos humanos, en http://www.ohchr.org/Documents/Publications/HR-PUB-14-2 SP.pdf (consultado el 17 de junio de 2018).

9 Vid. G. Gallego SÁnchez, "Marco jurídico internacional de protección de la mujer víctima de violencia", Revista de Jurisprudencia El Derecho, 2017, núm. 2, (EDB 2017/506744, www.elderecholefebvre).

${ }_{10}$ Naciones Unidas. Estudio a fondo sobre todas las formas de violencia contra la mujer. Informe del Secretario General, A/61/122/Add.1, 6 de julio de 2006, p. 118.

11 Sobre este derecho véase a J. F. LousADa Arochena, "El derecho fundamental a vivir sin violencia de género", Anales de la Cátedra Francisco Suárez, 2014, 48, pp. 31-48, en esp. pp. 46 y 47.

12 España ratificó esta Convención mediante Instrumento de ratificación de 16 de diciembre de 1983 (BOE núm. 69, de 21 de marzo de 1984). Para un repaso de dicha normativa véase E. Díez Peralta, "Los derechos de la mujer en el Derecho internacional", REDI, 2011, núm. 2, vol. LXIII, pp. 87-121; M. C. DíAz de Terán Velasco, "La transversalidad de género. Valoraciones a partir de algunos documentos de Naciones Unidas. Anuario Español de Derecho Internacional, 2015, vol. 31, pp. 323-347.

13 Ver la plataforma de Pekín en http://beijing20.unwomen.org/es/about.

14 BOE núm. 313, de 31 de diciembre de 1990.

15 El Comité de los Derechos del Niño de Naciones Unidas, singularmente, la Observación general núm. 13 de 2011 sobre el derecho del niño a no ser objeto de ninguna forma de violencia y, particularmente, las observaciones finales hechas a España, en esp. párr. 61. 
que los Estados tendrán que hacer todo lo posible para proteger a las y los niños que han vivido estas situaciones y ofrecerles una atención específica. Sin embargo, a pesar de este reconocimiento ${ }^{16}$, la ONU no ha logrado que se asevere explícitamente que la violencia de género afecta al interés superior de las y los menores, cuando el origen de su traslado ilícito fue debido a dicha violencia estructural ${ }^{17}$.

10. El Parlamento Europeo también viene solicitando a los Estados miembros y a la Comisión Europea que introduzcan la perspectiva de género en todas sus políticas, en particular en aquellas potencialmente relacionadas con la sensibilización y detección de la violencia hacia las mujeres, así como en las relativas a la protección y salvaguarda de la integridad de estas víctimas. Precisamente, la Directiva 2012/29/UE del Parlamento Europeo y del Consejo, de 25 de octubre de 2012, por la que se establecen normas mínimas sobre los derechos, el apoyo y la protección de las víctimas de delitos ${ }^{18}$, plasma la necesidad de dispensar una protección específica a las y los menores en escenarios de violencia de género, debido al elevado riesgo de victimización reiterada. De igual modo ha quedado reflejada en el Considerando K de la Resolución del Parlamento Europeo, de 25 de febrero de 2014, sobre recomendaciones destinadas a la Comisión sobre la lucha contra la violencia ejercida sobre las mujeres ${ }^{19}$.

11. Junto a las iniciativas del Parlamento, otras instituciones de la UE, en el ámbito de sus competencias, han adoptado instrumentos sobre reconocimiento mutuo de medidas de carácter penal ${ }^{20}$, con la finalidad de que a la víctima de violencia, especialmente la de género o doméstica, se le asegure su protección ante el traslado a cualquier Estado miembro. Por un lado, se aprueba la Directiva 2011/99/ UE del Parlamento europeo y del Consejo de 13 de diciembre de 2011 sobre la Orden Europea de Protección ${ }^{21}$ (en adelante OEP), traspuesta al ordenamiento español por la Ley 23/2014 de reconocimiento mutuo de resoluciones penales en la Unión Europea ${ }^{22}$ y, por otro, el Reglamento UE núm. 606/2013, de

${ }^{16}$ Véase NN.UU., Ocultos a plena luz. Un análisis estadístico de la violencia contra los niños, 2014, en http://www.un.org/ es/publications/publipl52.shtml (consultado el 25 de mayo de 2018), donde se reconoce que:" Con frecuencia, el desarrollo de los niños que han sido objeto de abusos graves o de abandono es inadecuado, y tienen dificultades de aprendizaje y desempeño escolar. También pueden tener bajos niveles de autoestima y sufrir depresión, lo que, en el peor de los casos, puede ser motivo de que adopten conductas de alto riesgo y comportamientos autodestructivos. Similares consecuencias pueden sufrir los niños que presenciaron episodios violentos. Los niños que crecen en hogares o comunidades violentas tienden a interiorizar esas conductas violentas como manera de resolver disputas y a repetir esas pautas de violencia y abuso contra sus cónyuges e hijos".

17 Vid. A. Powell \& S. Murray, "Children and domestic violence: Constructing a policy problem in Australia and New Zealand”, Social \& Legal Studies, 2008, 17 (4), pp. 453-473.

18 DOUE L 315/57, de 14 de noviembre de 2012. Esta Directiva ha sido transpuesta al ordenamiento español en la Ley 4/2015, de 27 de abril, del Estatuto de la víctima del delito (BOE núm. 101, de 28 de abril de 2015).

19 DOUE C 285/2, de 29 de agosto de 2017.

${ }^{20}$ Las medidas de protección otorgadas por los Estados miembros pueden ser de Derecho administrativo, penal o civil por su naturaleza y su duración, ámbito de aplicación y procedimientos de aprobación varían entre los Estados miembros. El proyecto «Epogender» y sus manuales están disponibles para poder consultar el análisis comparativo de la legislación y práctica de los Estados miembros afectados por la Directiva 2011/99/UE sobre la Orden Europea de Protección en lo que respecta a las medidas de protección de las víctimas de la violencia de género. Véase también M. DE Hoyos SANCHo, "El reconocimiento mutuo de las medidas de protección penal y civil de las víctimas en la Unión Europea. La Directiva 2011/99, el Reglamento 606/2013, y su respectiva incorporación a los ordenamientos español y alemán”, Revista de proceso y derecho penal, 2015, núm. 38, pp. 63-105; ID.," La orden de protección a las víctimas de la violencia de género", Tutela jurisdiccional frente a la violencia de género, Valladolid, 2009, pp. 521 y ss. Un análisis comparado con los sistemas italiano, portugués, alemán y austriaco puede encontrarse en los capítulos que R. CABrera Mercado (COORD.), Análisis de medidas para mejorar la protección policial y judicial de las víctimas de la violencia de género, Madrid, 2011, pp. 93 y ss., en http://www.mimp.gob.pe/files/programas nacionales/pncvfs/Proyecto_Apoyo Asociacion_Juristas/Analisis_Medidas_Mejorar_Proteccion_Policial_Judicial_Victimas violencia_Genero.pdf. (consultado el 20 de junio de 2018).

${ }^{21}$ DOUUE L 338/2, 21 de diciembre de 2011 que instituye un mecanismo entre los Estados miembros que permite el reconocimiento de las órdenes de protección dictadas como medidas de Derecho penal. El beneficiario de una orden de protección de Derecho penal dictada en un Estado miembro, puede solicitar una orden de protección europea con un procedimiento simplificado y acelerado, debe concedérsele protección a través de la nueva medida de protección adoptada por el Estado miembro al que viaja o se desplaza. En España se ha traspuesto en la Ley 23/2014, de 20 de noviembre, de reconocimiento mutuo de resoluciones penales en la Unión Europea (BOE núm. 282, de 21 de noviembre de 2014).

${ }^{22}$ BOE núm. 282, de 21 de noviembre de 2014. Sobre dicha normativa véase T. FreIXES y L. RomÁn (DIRS.), La orden europea de protección. Su aplicación a las víctimas de violencia de género, Tecnos, Madrid, 2015, en http://158.109.137.58/ epogender2/images/news/Libro/LA_ORDEN_EUROPEA_DE_PROTECCION.pdf (consultado el 13 de junio de 2018). 
12 de junio de $2013^{23}$ sobre el reconocimiento mutuo de medidas de protección en materia civil ${ }^{24}$. Este tipo de regulación implica el rápido y fácil reconocimiento en toda la UE, merced a un simple procedimiento de certificación, de las órdenes de alejamiento, protección y restricción emitidas por la autoridad competente. Con dicho sistema, la víctima de violencia de género que ha sustraído ilícitamente a sus hijas o hijos podría acompañarles ante una decisión obligada de retorno al país de la residencia habitual. Sin embargo, nos preocupa la inoperante coordinación y comunicación entre los Estados miembros durante la ejecución de una OEP. Desde el Parlamento Europeo, se viene demandando a los países de la UE que mejoren y potencien conjuntamente dicho procedimiento, además de las necesarias acciones transfronterizas simultáneas, puesto que generaría más eficienci ${ }^{25}$. En todo caso, tendremos ocasión de analizarlo en el epígrafe dedicado a las medidas de seguridad para un retorno seguro.

12. Al margen de esta legislación de la Unión, tal y como hemos anunciado, existe otro texto internacional que vincula a España en este ámbito: el Convenio de Estambul, una aportación regional europea del Consejo de Europa para la lucha contra la violencia contra la mujer y las niñas, alcanzando su aplicación a la protección de los hijos e hijas de las víctimas de la violencia de género o doméstica. Precisamente, el Parlamento Europeo insiste a la UE que se adhiera a dicha convención y solicita a los Estados miembros que todavía no lo hayan hecho que lo ratifiquen, asignando recursos financieros y humanos suficientes para ponerlo en práctica.

13. Lo destacable del Convenio de Estambul es el empleo de una noción amplia de la vilencia, que incluye cualquier variedad de violencia hacia la mujer incluida la doméstica, extensión conceptual que viene siendo criticada por parte de la doctrina española ${ }^{26}$. Estas definiciones se encuentran recogidas en los apartados a, b, y d del art. 3 del Convenio, que distingue entre "violencia contra las mujeres" "violencia doméstica" ${ }^{28}$ y "violencia contra las mujeres por razones de género"29. Y es que, en los distin-

${ }^{23}$ DOUE L 184/4, de 29 de junio de 2013, normativa que debe aplicarse a las medidas de protección dictadas en un Estado miembro con el objeto de proteger a una persona cuando existan motivos fundados para considerar que su vida, su integridad física o psíquica, su libertad personal, su seguridad o su integridad sexual están en peligro.

24 Hay que llamar la atención con el título de este Reglamento, ya que la terminología utilizada en él puede suscitar equívocos. Dicho instrumento no regula el reconocimiento de medidas de protección "en materia civil" en el sentido del Derecho privado, sino que para el ordenamiento español son medidas de protección penal derivadas de la comisión de un hecho delictivo. Por ejemplo, se refiere a las medidas cautelares o como parte de la pena, tales como prohibiciones o limitaciones de libertad de movimiento o de comunicación del maltratador en relación con la víctima. En otros ordenamientos jurídicos de los Estados miembros, este tipo de medidas se adoptan en el orden procesal civil e, incluso, pueden ser de naturaleza administrativa asistencial. De ahí la pertinencia de regular su reconocimiento mutuo y ejecución en otros Estados miembros a través de un instrumento normativo de la UE diferente al del reconocimiento de medidas judiciales dictadas desde el orden penal, y con fundamento en el 81 TFUE, y no en el 82 TFUE, que es el relativo a la cooperación penal.

25 Resolución del Parlamento Europeo, de 19 de abril de 2018, sobre la aplicación de la Directiva 2011/99/UE sobre la Orden Europea de Protección (2016/2329(INI)).

${ }^{26}$ Algunas voces doctrinales españolas consideran que la confusión terminológica entre la violencia de género y doméstica desactiva el componente destructurador del moderno Derecho antidiscriminatorio, lo que supone un paso atrás en la lucha por la erradicación de la discriminación estructural de la violencia de género. El nuevo Derecho antidiscriminatorio y de antisubordinación exige romper con una estructura de trabajo desfasada de funcionamiento del fenómeno jurídico, y de los criterios básicos de igualdad centrados en un contexto individual, que no estructural y grupal. Esta tarea ardua apenas se acaba de acometer desde el Derecho y desde el pensamiento crítico del Derecho. Sobre la temática véase J. Ma. GiL RuIz, "La mujer del discurso jurídico: una aportación desde la teoría crítica del Derecho", Quaestio Iuris, 2015, vol. 8, núm. 3, pp. 1441-1480, en esp. p. 1474; ID., "La Filosofía del Derecho: Entre un nuevo Derecho amenazado y una ciencia jurídica desfasada", Anuario de Filosofía del Derecho, 2014, vol. XXX, pp. 241-270, en esp. pp. 243-244; ID., "Los Informes de Evaluación de Impacto de Género (IEIG) como garantía del gender mainstreaming y su incidencia en la normativa y jurisprudencia española”, Revista Vasca de Administración Pública, 2012, núm. 92, pp. 17-55; M. A. BARRĖre, Discriminación, Derecho antidiscriminatorio y acción positiva a favor de las mujeres, Madrid, Cuadernos Cívitas, 1997; ID., "La interseccionalidad como desafío al mainstreaming de género en las políticas públicas”, Revista Vasca de Administración Pública, 2010, núm. 87-88, pp. 240-241.

27 “... todos los actos de violencia basados en el género que implican o pueden implicar para las mujeres daños o sufrimientos de naturaleza física, sexual, psicológica o económica, incluidas las amenazas de realizar dichos actos, la coacción o privación arbitraria de libertad, en la vida pública o privada".

28 “...todos los actos de violencia física, sexual, psicológica o económica que se producen en la familia o en el hogar o entre cónyuges o parejas de hecho antiguos o actuales, independientemente de que el autor del delito comparta o haya compartido el mismo domicilio que la víctima".

29 “...toda violencia contra una mujer porque es una mujer o que afecte a las mujeres de manera desproporcionada". 
tos Estados participantes, uno de los problemas detectados en la protección de las víctimas de violencia de género es la inexistencia de un marco conceptual particular. De cada normativa estatal se infiere una diversidad de nociones, de las que dependen a su vez los ámbitos de protección sustantivos y subjeti$\operatorname{vos}^{30}$. En todo caso, se debería partir de una concepción de violencia de género que se caracterice por el género de la persona contra la que se ejerce y no por el ámbito en el que se produce ${ }^{31}$. No obstante, a pesar del riesgo que conlleva la equiparación de los términos violencia de género o conyugal/pareja o violencia doméstica, desde el punto de vista de las situaciones privadas internacionales, se considera aconsejable utilizarlos indistintamente. La expresión "violencia doméstica" en algunas normativas estatales se usa para referirse predominantemente a la "violencia conyugal" o a la "violencia en la pareja". Igualmente, dicha terminología aparece en los informes realizados en el seno de la Conferencia de La Haya de Derecho internacional privado. En todo caso, lo verdaderamente relevante es si esta violencia machista repercute en las y los hijos que son objeto de sustracciones internacionales y si el Convenio de Estambul va a contribuir a la armonización de los niveles de protección para estas víctimas. Justamente, en el Considerando X de la Resolución del Parlamento Europeo, de 12 de septiembre de 2017, sobre la propuesta de Decisión del Consejo relativa a la celebración por la Unión Europea del Convenio de Estambul ${ }^{32}$, se vuelve a confirmar que “...los menores no tienen que verse expuestos directamente a la violencia para ser considerados víctimas, ya que la violencia doméstica también genera consecuencias traumáticas en quien la presencia".

14. Por otro lado, el art. 1 del Convenio de Estambul establece un mecanismo de cooperación internacional desarrollado en los arts. 62 a 64 de dicho texto ${ }^{33}$ para que los Estados parte queden obligados a celebrar acuerdos de cooperación en materia civil y penal, a fin de prevenir, combatir y perseguir todas las formas de violencia hacia las mujeres y proteger y asistir a las víctimas; investigar los delitos, aplicar las sentencias y las órdenes de protección, denunciar desde el país de residencia hechos cometidos en otro Estado parte, y dar asistencia judicial en materia de extradición o de ejecución de sentencias civiles o penales dictadas en otro Estado (art. 62). Del mismo modo, los países participantes deben transmitir información con agilidad sobre el riesgo de una persona y a asegurarse de que sean adoptadas las medidas de protección apropiadas en el país donde se encuentra la víctima. De esta forma, el otro Estado parte podrá prevenir, entablar o perseguir los procedimientos pertinentes en relación con los delitos establecidos en el Convenio de Estambul (arts. 63 y 64). Sin duda, esta vía de cooperación desde ambos ámbitos favorecerá el eje vertebrador para combatir la violencia de género transnacional entre los Estados participantes.

15. En relación a la temática estudiada, lo relevante viene determinado en el apartado primero del art. 31 del Convenio de Estambul, que insta a los gobiernos a legislar para que "en el momento de estipular los derechos de custodia y visita relativos a los hijos, se tengan en cuenta los incidentes de violencia incluidos en su ámbito de aplicación". Asimismo, el apartado segundo del mismo precepto reconoce que se debe proporcionar seguridad a las víctimas y a sus hijas e hijos en el ejercicio del derecho de visita o custodia, cuando a estas personas menores y sus derechos se les pongan en peligro. La implementación de este precepto en el sistema del CLH de 1980 podría derivar en que, entre los motivos de oposición al retorno inmediato de los y las menores, se pudiera invocar la violencia de género/doméstica ${ }^{34}$. Si ello no es posible, prestaremos atención a lo dispuesto en el art. 31 del Convenio de Estambul para reinterpretar el art. 13 del CLH 1980 de forma extensiva, subsumiendo en su ámbito de aplicación las situaciones de

\footnotetext{
30 T. FREIXES Y L. RoMÁn (DIRS.), La orden europea de protección..., op. cit., pp. 46-50.

31 J. Ma. GIL RuIZ, "Catarsis del derecho ante la subordiscriminación”, J. Ma. GIL RuIz (coord.), El Convenio de Estambul como marco del Derecho antisubordiscriminatorio, Madrid, Edit. Dykinson, 2018, pp. 23-28 (en prensa).

32 P8_TA(2017)0329, en http://www.europarl.europa.eu/

33 Vid. G. Gallego SÁnchez, "El Convenio de Estambul. Su incidencia en el sistema español de lucha frente a la violencia contra la mujer”. Revista de Jurisprudencia El Derecho, 2015, núm. 2 (EDC 2015/195775, www.elderecholefebvre).

${ }^{34}$ Sobre esta cuestión, vid. M. EsLava Rodríguez, "Secuestro internacional de menores y violencia doméstica", P.-V. CANOMaíllo Rey (Dir.), Los juicios rápidos. Orden de protección: análisis y balance, Madrid, Consejo General del Poder Judicial, 2004, pp. 131-181.
} 
violencia que sufre la madre y la repercusión negativa en las y los hijos ${ }^{35}$. Desde nuestro punto de vista, dos conclusiones se pueden extraer del art. 31 del Convenio de Estambul en relación a la sustracción de menores originada por la violencia machista: 1) la autoridad de origen que sea parte del Convenio de Estambul y que resulte competente para resolver los temas de responsabilidad del menor quedará obligada por lo preceptuado en el art. 31 si en dicho asunto existen episodios de violencia de género; 2) también queda vinculada a lo dispuestos en dicho precepto la autoridad requerida de un Estado participante que tenga que decidir sobre el retorno de la o del niño cuando se acredite violencia de género. En dicho procedimiento se deben adoptar todas las medidas de seguridad que estén a su alcance, principalmente si la resolución definitiva va encaminada al retorno seguro al país de la residencia habitual.

16. En estos momentos, uno de los grupos políticos que conforma el Parlamento Europeo plantea la posibilidad de implementación de lo dispuesto en el Convenio de Estambul en la reforma del Texto de Refundición del RBr. II bis ${ }^{36}$. En este sentido, la Resolución legislativa del Parlamento Europeo, de 18 de enero de 2018, sobre la propuesta de Reglamento del Consejo relativo a la competencia, el reconocimiento y la ejecución de resoluciones en materia matrimonial y de responsabilidad parental, y sobre la sustracción internacional de menores (refundición) ${ }^{37}$ introduce ciertas enmiendas, como las de los considerandos 17 y 18, que atienden a los casos excepcionales de violencia de género o doméstica. Sin embargo, opinamos que interesaría implementar el Convenio de Estambul, haciendo referencia expresa al mismo tanto en los considerandos como en los articulados del Texto de Refundición que definitivamente se adoptara. Esta técnica no resulta extraña, ya que en el actual RBr. II bis incorpora ciertos preceptos del CLH 1980 en el articulado sobre sustracción internacional de menores. El paraguas normativo del Convenio de Estambul debe estar presente en la reforma del RBr. II bis, instrumento marco en materia de familia y menores. Esta integración podría reducir, e incluso, erradicar las sustracciones ilícitas de menores originadas como consecuencia de la violencia de género, aunque para ello es necesaria una verdadera voluntad política en la prevención y lucha contra la violencia de género y, sobre todo, la implantación de un marco jurídico coherente que proteja a estas víctimas en todos los ámbitos.

\section{El impacto del Convenio de Estambul en la legislación española sobre sustracción internacional de menores}

17. En España, la violencia de género viene ocupando un lugar importante en el debate social y mediático, impulsando una avalancha de reformas legislativas encaminadas a erradicar esta lacra de devastadoras consecuencias personales, familiares y sociales. La Ley integral 1/2004 representó un avance en la protección a las víctimas de violencia de género, si bien su puesta en marcha no ha tardado en revelar sus lagunas y carencias ${ }^{38}$, hecho que ha originado su inmediata revisión para ser ajustada a las

35 En este sentido vid. Ma V. CuARteto Rubio, "La alegación de violencia doméstica en el proceso de restitución internacional de menores", M. T. MARTín LóPEZ (Coord.), La igualdad de género desde la perspectiva social, jurídica y económica, Cizur Menor, Civitas, 2014, p. 88; P. Maestre CASAs, "Violencia doméstica y sustracción internacional de menores", A. Figueruelo BuRrieza (Dir.), Derechos y libertades en la sociedad actual, Granada, Comares, 2014, pp. 73 y 75.

${ }^{36}$ En la elaboración de la refundición del RBr. II bis, existe una opinión de la ponente $<$ Depute $>$ Soledad Cabezón Ruiz (PSOE) emitida en la comisión de peticiones para la comisión de Asuntos Jurídicos, de 15 de mayo de 2017, 2016/0190 (CNS) con el objetivo de implementar lo contenido en el Convenio de Estambul en el nuevo texto del RBr. II bis. La propuesta parte del considerando 17 del Texto de Refundición, que dispone: "En caso de urgencia, las disposiciones del presente Reglamento no impedirán que las autoridades de un Estado miembro que no sean competentes para conocer del fondo del asunto adopten medidas provisionales, incluidas las protectoras, por lo que se refiere a la persona o a los bienes de un niño que se encuentren en ese Estado miembro o, en caso de violencia doméstica o de género, con arreglo a la definición del Convenio del Consejo de Europa sobre prevención y lucha contra la violencia contra las mujeres y la violencia doméstica (Convenio de Estambul). El Considerando 18 va en esta línea: "Merece una atención especial el hecho de que, en casos excepcionales, como los de violencia doméstica o de género, las autoridades del Estado miembro de la residencia habitual del menor pueden no ser la autoridad más apropiada para conocer del asunto de responsabilidad parental".

37 P8_TA-PROV(2018)0017, en http://www.europarl.europa.eu_(consultado el 5 de julio de 2018).

38 Para el legislador español, la violencia de género es entendida como aquella manifestación de discriminación y desigualdad originada por la relación de poder del hombre sobre la mujer, cuando ha sido ejercida por quienes sean o hayan sido sus cónyuges o por quienes estén o hayan estado ligados a ellas por relaciones similares de afectividad, aun sin convivencia (art. 1 de la Ley integral 1/2004). Y es que la categoría violencia de género escogida por la normativa interna española es heredera de 
necesidades más apremiantes derivadas de esta problemática. Particularmente, existe una convicción de que la violencia de género no solo afecta a las mujeres, sino también a sus hijas o hijos que son, en la mayoría de las ocasiones, instrumentalizados para seguir perpetuándola. En consecuencia, el legislador español se le plantea la necesidad de dar una respuesta legislativa acorde con esta realidad.

18. La Ley Orgánica 1/1996, de protección jurídica del menor y las previsiones del Código Civil en esta materia, fueron entonces el principal marco regulador de los derechos de los y de las menores de edad. Sin embargo, resultaron insuficientes ante los importantes cambios sociales y la repercusión de la violencia de género en aquellos y aquellas, por lo que se reclamaba una mayor protección jurídica para dar cumplimiento efectivo al art. 39 de la Constitución española y a las normas internacionales ya mencionadas.

19. El Protocolo Básico de Intervención contra el Maltrato Infantil de $2014^{39}$ reconoció que la exposición de las y los menores a la violencia de género es una forma del maltrato infantil, lo que reclama una atención especializada. De este afirmación se hizo eco el preámbulo de la Ley 8/2015, de 22 de julio, de modificación del sistema de protección a la infancia y a la adolescencia ${ }^{40}$, al disponer que "la exposición de los menores a esta forma de violencia en el hogar, lugar en el que precisamente deberían estar más protegidos, los convierte también en víctimas de la misma"41. Del mismo modo, el art. 11.2 apartado i) de la Ley 26/2015, de 28 de julio, de modificación del sistema de protección a la infancia y a la adolescencia ${ }^{42}$ recoge que uno de los principios rectores en materia de menores es el amparo por parte de los poderes públicos contra toda forma de violencia, incluido el maltrato físico o psicológico, los castigos físicos humillantes y denigrantes, el descuido o trato negligente [...] y la violencia de género en el ámbito familiar. Esta Ley ha tenido el mérito de reforzar la lucha contra la violencia de género, garantizando los derechos de los colectivos más vulnerables, en particular, el de menores. Para ello se propone un marco jurídico de intervención de las autoridades públicas ante situaciones de violencia de género que les puedan afectar (art. 11 y art. 12 de dicha normativa). Así, el art. 1 de la Ley integral $1 / 2004^{43}$ reconoce, en su nuevo apartado segundo, que el daño causado a las y los niños por exposición a violencia familiar es un perjuicio directo al menor ${ }^{44}$. Se trata, por tanto, de una respuesta que sintoniza con otras legislaciones estatales modernas en Derecho comparado ${ }^{45}$ y que acaba repercutiendo en la Ley

significados asignados desde diversos ámbitos y saberes extrajurídicos: psicología, sociología, politología, antropología, teorías feministas, que debe ser asumido y "traducido" por la dogmática jurídica. En consecuencia, son todas aquellas agresiones que se producen en el ámbito privado en el que el agresor, generalmente varón, tiene una relación de pareja con la víctima.

39 Véase el Protocolo básico de intervención contra el maltrato infantil en el ámbito familiar: actualizado a la intervención en los supuestos de menores de edad víctimas de violencia de género. Madrid. Ministerio de Sanidad, Servicios Sociales e Igualdad, 2014, http://www.msssi.gob.es/biblioPublic/publicaciones/home.htm (consultado el 26 de mayo de 2018).

40 BOE núm. 175, de 23 de julio de 2016.

41 Particularmente, se aclara que esta forma de violencia afecta a los menores, no solo porque condiciona su bienestar y desarrollo, llegando a causarles incluso serios problemas de salud, sino también porque los convierte en un instrumento para que el maltratador ejerza su dominio y violencia sobre la mujer, favoreciendo la transmisión intergeneracional de estas conductas violentas sobre la mujer.

42 BOE núm. 180, de 29 de julio de 2015.

43 La Disposición final tercera de la Ley 8/2015 es la encargada de introducir la modificación del art. 1 de la Ley integral $1 / 2004$.

${ }^{44}$ Por tanto, se entiende por víctima directa "a toda persona física que haya sufrido un daño o perjuicio sobre su propia persona o patrimonio, en especial lesiones físicas o psíquicas, daños emocionales o perjuicios económicos directamente causados por la comisión de un delito". Dentro de este concepto quedan los y las menores que viven en entornos de violencia de género, dada las alteraciones que para su desarrollo supone la exposición a la violencia, superando así el concepto de víctima indirecta que establecía la Ley 1/2004 para los y las menores que no sufrían agresiones. Sobre el concepto de víctimas directas e indirectas véase J. L Manzanares SAmAniego, "Estatuto de la víctima: Comentario a su regulación procesal”, Diario La Ley, 2014, núm. 8351 (LA LEY 4596/2014, www.laleydigital.laley.es).

${ }^{45}$ El Derecho inglés reconoce que si un niño presencia o escucha violencia doméstica, el menor deberá ser protegido. El significado de daño a un menor comprende, por tanto, las "deficiencias sufridas por ver o escuchar los malos tratos ocasionados a otra persona" (modificación introducida en la Ley sobre niñez de 1989 [Children Act 1989, Section 31(9) (b)] por la Ley de Adopción y Niños de 2002 (Adoption and Children Act 2002). Dicha normativa está disponible en http://www.legislation.gov. uk/ukpga/1989/41/section/31. Asimismo, la Ley sobre Violencia Doméstica de Nueva Zelanda de 1995 (New Zealand Domestic Violence Act n. 86, 1995), contiene en su Parte 1, la sección 3(3)(a) y 3(3)(b)) la definición de abuso psicológico de un niño 
4/2015 del Estatuto de la víctima del Delito, cuando reconoce como víctimas a las y los menores que se encuentran en un entorno de violencia de género para que accedan a los servicios de asistencia, de apoyo y se adopten medidas de protección (art. 10). Estos cambios se deben, fundamentalmente, a la adaptación de la legislación interna española a los dictados del Convenio de Estambul.

20. Más allá de los principios y del contenido de las reformas operadas en 2015 , el reconocimiento de las y los hijos como víctimas directas de la violencia de género obliga a que la autoridad judicial competente se pronuncie sobre la pertinencia de la adopción de medidas cautelares y de aseguramiento, entre otras, la orden de protección, la salida del domicilio, alejamiento, la suspensión de comunicaciones, la patria potestad o la custodia y el régimen de visitas del inculpado con sus descendientes (art. 544 quinquies de la Ley de Enjuiciamiento Criminal) ${ }^{46}$.

21. La falta de conexión de los traslados ilícitos de menores con la violencia machista se evidencia, una vez más, en el procedimiento interno vigente en España en procesos de sustracción internacional de menores. Concretamente, en el Capítulo IV bis del Título I del Libro IV de la LEC, integrado por los arts. 778 quáter a 778 sexies, bajo la rúbrica "medidas relativas a la restitución o retorno de menores en los supuestos de sustracción internacional" ${ }^{47}$, Dicho proceso no contiene remisión alguna a la normativa que regiría para la restitución en relación a un menor expuesto a la violencia de género y si el procedimiento podría quedar bajo la competencia especial del Juzgado de Violencia de género. Actualmente, dicho juzgado es el órgano competente para la problemática del secuestro internacional de menores, siempre que la violencia de género fuese cometida en España o, si no es así, se den el resto de los presupuesto del art. 23.4 1) de la LOPJ. Su competencia se basa en los arts. 87 ter 2 d) de la LOPJ y 44 de la Ley integral 1/2004, en relación con la transcendencia del asunto civil vinculado a la medida de retorno del hijo de la víctima y siempre que se cumplan el resto de presupuestos del punto 3 del art. 87 ter de la LOPJ. Ello queda confi mado, entre otros, en el AAP de Madrid de 31 de marzo de $2015^{48}$, donde se estima la competencia objetiva de un Juzgado de Violencia sobre la Mujer para el conocimiento de un procedimiento sobre sustracción internacional de menores. Cuando se decida abordar una reforma acorde con la medida que se ha incorporado en el pacto de Estado de lucha contra la violencia de género ${ }^{49}$, estos juzgados especiales podrían atribuirse la competencia en los asuntos civiles y penales derivados de restitución ilícita de menores que tengan como origen la violencia de género. Para ello será necesario reformar la competencia de los tribunales españoles mediante LOPJ, Ley Enjuiciamiento criminal y civil, con el fin de lograr una adecuada protección a la mujer y a sus hijos, de acuerdo con lo que viene establecido en el Convenio de Estambul.

22. En definitiva, la protección de la legislación material española en relación a la experiencia victimizante de las y los menores en situaciones de violencia de género ${ }^{50}$ deja mucho que desear en situaciones de sustracción internacional. El mandato de la normativa interna española, particularmente el art. 1 de la Ley integral 1/2004, obliga a considerarlos como víctimas directas de la violencia de género,

comprende: "a) ocasionar o permitir que el niño vea o escuche el abuso físico, sexual o psicológico ocasionado a una persona con la que el niño tiene una relación doméstica; b) pone al niño o permite ponerlo en un verdadero riesgo de ver o escuchar que se produce ese abuso". El texto normativo está disponible en http://www.legislation.govt.nz/act/public/1995/0086/latest/ DLM371926.html, (consultado 17 de septiembre de 2017).

${ }^{46}$ Véase el gran trabajo de análisis jurisprudencial y doctrinal sobre la repercusión de la violencia de género en menores de P. Reyes Cano, "La suspensión del "derecho de visitas" en contextos de violencia de género: resistencias patriarcales", Ma . GIL Ruiz (coord.), El Convenio de Estambul como marco del Derecho antisubordiscriminatorio, Madrid, Edit. Dykinson, 2018, pp. 203-244, esp. pp. 214-218 (en prensa). A. DíAz VelázQuez, "Violencia de género y guarda y custodia compartida", Ed. Jurídica Sepín, agosto 2017, en https://www.sepin.es.

47 Este nuevo procedimiento ha sido introducido por la Ley 15/2015, de 2 de julio, de la Jurisdicción Voluntaria (BOE núm. 158, de 3 de julio de 2015). Véase Circular 6/2015 de la Fiscalía General del Estado, sobre aspectos civiles de la sustracción internacional de menores.

48 (EDJ 2015/57382, www.elderecholefebvre).

49 Según Ponencia que estudia la elaboración de estrategias contra la violencia de género, constituida en el seno de la Comisión de Igualdad. XII Legislatura, BOCGE, Senado, núm. 131, de 28 de julio de 2017.

${ }^{50}$ Dicha experiencia se puede consultar en el Informe llevado a cabo por Amnistía Internacional (2015). España. Informe al Comité sobre la Eliminación de la Discriminación contra la Mujer de la ONU, p. 7. 
correspondiendo a los jueces competentes su interpretación a la hora de apreciar si existe grave riesgo en la restitución al contexto paterno, barajando medidas más aptas para hacer efectivo un retorno seguro o, en su caso, denegarla si no se lograra tal fin

\section{Interconexión de la violencia de género y el grave riesgo para la no restitución en situaciones europeas}

\section{El grave riesgo de las y los menores en escenarios de violencia de género}

23. El CLH de 1980 es el principal texto internacional para dar protección a las y los menores sustraídos que articula mecanismos para su pronta restitución al lugar de la residencia habitual a través de la cooperación internacional de autoridades centrales ${ }^{51}$. Su aplicación es complementada por otros dos textos internacionales: el RBr. II bis y el Convenio relativo a la competencia, la ley aplicable, el reconocimiento y ejecución y la cooperación en materia de responsabilidad parental y medidas de protección de los niños, hecho el 19 de octubre de $1996^{52}$ (en adelante CLH 1996), cuya intervención dependerá de si el traslado del o de la menor es dentro de Estados miembros de la UE que aplican el RBr. II bis o, en su caso, entre Estados participantes del CLH $1996^{53}$ y no vinculados a dicho instrumento europeo ${ }^{54}$. Por tanto, en este trabajo dejaremos a un lado estas últimas situaciones para centrar la problemática de los desplazamientos o retenciones ilícitas entre Estados participantes del Reglamento.

24. Ni el RBr. II bis ni el CLH 1980 contienen respuesta expresa en relación con la sustracción internacional de menores originada por una situación de violencia de género ${ }^{55}$. La única referencia transversal a la cuestión la encontramos en el art. 13.b) CLH 1980 cuando establece la posibilidad de no restitución del o de la menor que ha sido expuesto a un peligro grave físico o psíquico o si, de cualquier otra manera, se da una situación intolerable ${ }^{56}$.

25. En la práctica, esta excepción viene siendo utilizada con el objetivo de dilatar el proceso, como pueda ser la integración del menor en el país donde ha sido retenido para que no sea devuelto. El uso fraudulento del art. 13.b) CLH 1980 ha provocado que las verdaderas situaciones de grave riesgo para las y los hijos de las víctimas de la violencia de género queden desprotegidas ${ }^{57}$.

51 Existen distintos instrumentos internacionales que contienen normas de competencia judicial internacional, de ley aplicable, de reconocimiento y ejecución de decisiones, así como mecanismos de cooperación entre autoridades centrales en relación a la temática de la responsabilidad parental y sustracción internacional de menores, como el Convenio Europeo de Luxemburgo de 20 de mayo de 1980, sobre reconocimiento y ejecución de las sentencias sobre custodia de los hijos, del que España forma parte (BOE núm. 210, de 1 de septiembre de 1984. Por otra parte, para España también está vigente el Convenio con Marruecos sobre asistencia judicial, reconocimiento y ejecución de resoluciones judiciales en materia de derecho de custodia y derecho de visita y devolución de menores, de 30 de mayo de 1997 (BOE núm. 150, de 24 de junio de 1997).

52 BOE núm. 291, de 2 de diciembre de 2010.

53 Vid. P. LAGARDE, Informe explicativo del CLH 1996, Texto adoptado por la XVIII Sesión, Oficina permanente de la Conferencia de La Haya, Holanda, 1996, párrafo 46. También A. BorRÁs, "Comisión especial sobre el funcionamiento práctico del Convenio de La Haya de 1980 sobre sustracción de menores (30 de octubre a 9 de noviembre de 2006)”, REDI, 2006, núm. 2, pp. 1110-1116; ID., "Consejo sobre los Asuntos Generales y la Política de la Conferencia de La Haya de Derecho internacional privado (7-9 de abril de 2010)", REDI, 2010, núm.1, pp.323-329.

54 Véase el art. 61 del RBr. II bis, establece la respuesta sobre una posible colisión con las reglas del CLH 1996.

55 Los redactores del Convenio pensaron en evitar otros supuestos diferentes. Véase el Informe explicativo del Convenio de La Haya de 1980 realizado por la profesora E. Pérez Vera.

56 El «grave riesgo», el «daño físico o psíquico» y la «situación intolerable» son los conceptos clave del art. 13.b) del CLH 1980. Sobre estos conceptos véase, entre otros, R. S. PAZ LAMELA, "Causas de no restitución del menor en los supuestos de sustracción internacional (Análisis a través de la jurisprudencia reciente)", Anuario da Facultade de Dereito da Universidade da Coruña, 2013, núm. 17, pp. 675-685. En general, sobre la interpretación de este precepto, $c f r$. P. BEAumONT and P. McELEAVy, The Hague Convention on International Child Abduction, Oxford University Press, 1999, pp. 135-176.

57 Desde hace tiempo, el art. 13.b) CLH 1980 es utilizado como «paraguas» de la violencia doméstica. Por ello, la Conferencia de La Haya considera que debe tratarse el tema, pero no hay acuerdo sobre lo que expresamente debe hacerse. La Comisión especial sobre el funcionamiento práctico de los Convenios de La Haya así lo vienen reconociendo. Vid. A. BorRÁs Rodríguez, "Reunión de la Comisión especial sobre el funcionamiento práctico del Convenio de La Haya de 1980 sobre 
26. La Comisión especial de La Haya viene alertando del insuficiente reconocimiento en el ámbito judicial de los efectos nocivos de la violencia de género sobre las y los niños cuando los malos tratos estén dirigidos primordialmente a su madre y el impacto que ello produce en el retorno al lugar de residencia habitual ${ }^{58}$. A pesar de que este organismo internacional no se plantee revisar el CLH 1980, si es consciente de sus carencias y de las necesidades de adaptación a los cambios sociales ${ }^{59}$, tal y como ocurre con la existencia y los efectos aterradores de la violencia machista ${ }^{60}$.

27. En el marco de mejoras de la aplicación del CLH 1980, la Comisión especial ha elaborado algunas recomendaciones, declaraciones, principios generales y/o guías de buenas prácticas, propugnando también el uso de potenciales hand books o bench books ${ }^{61}$. Entre estas acciones destaca el Proyecto o Propuesta de Guía de Buenas Prácticas sobre el art. 13.b) del CLH 1980², elaborado por la

sustracción internacional de menores y del Convenio de La Haya de 1996 sobre protección de niños, de 1 a 10 de junio de 2011", REDI, 2011, vol. LXIII, núm. 2, pp. 315-318; ID., "Reunión de la Comisión especial sobre el funcionamiento práctico del Convenio de La Haya de 1980 sobre sustracción internacional de menores y del Convenio de La Haya de 1996 sobre protección de niños, $2^{\mathrm{a}}$ parte, del 25 al 21 de enero de 2012”, REDI, 2012, vol. LXIV, núm. 2, pp. 308-309. Toda la documentación relativa a la reunión y, en particular, sus conclusiones y recomendaciones pueden consultarse en www.hcch.net, en «trabajos en curso» y «conclusiones y recomendaciones». Según N. GonZÁlez MARTín el abuso de esta excepción permite una desvirtualización de la naturaleza de la normativa internacional, en donde: por una parte, los padres pueden buscar dilaciones indebidas a través de la regla de excepcionalidad del plazo de un año invocando la adaptabilidad del menor a su nuevo entorno (art. 12, párrafo segundo) o la manipulación o falsedad de un grave riesgo, como la violencia doméstica (art. 13.b), dejando indefensos aquellos casos que sí merecen dicha invocación y protección y, por otra parte, los órganos judiciales competentes para resolver sobre la restitución, se decantan por aceptar excepciones a destajo, quizás con una tendencia o inercia hacia la protección doméstica de quienes sustraen o son sustraídos al coincidir, en un número importante de casos, con sus orígenes nacionales, es decir, quienes sustraen lo suelen hacer al territorio del cual se consideran connacional con la idea de que un tribunal nacional emitirá una decisión a su favor. Vid. N. GonZÁlez MARTín, "Sustracción internacional parental de menores y mediación. Dos casos para la reflexión: México (amparo directo en revisión 903/2014) y los Estados Unidos de América (Lozano v. Montoya Álvarez)”, REEI, 2015, núm. 29, pp. 268-304.

${ }^{58} \mathrm{Tal}$ y como afirma el documento sobre la "violencia doméstica y familiar y el grave riesgo de la excepción del art. 13.b) del CLH 1980 (Prel. Doc. No 9 de mayo de 2011), en https://assets.hcch.net/docs/ce5327cd-aa2c-4341-b94e-6be57062d1c6. pdf (consultado el 20 de junio de 2018). Afirmación expuesta en las sesiones previas a la Séptima Reunión de 12 de julio de 2017 de la Comisión Especial sobre el funcionamiento la Convención de La Haya sobre Sustracción de Menores de 1980 y el Convenio de La Haya de 1996 protección de los menores, que incluye, entre otras, aseveraciones cada vez más frecuentes de la violencia doméstica y familiar planteada bajo la grave defensa del riesgo grave hacia el menor, en https://assets. hcch.net/docs/0a0532b7-d580-4e53-8c25-7edab2a94284.pdf. Asimismo, se reconoce el creciente número de alegaciones de violencia intrafamiliar en procesos de sustracción internacional de menores en el marco de lo previsto en el art. 13.b) del CLH y el art. 11.b de la Convención Interamericana, por lo que se impone su ponderación a la luz de los objetivos de los Convenios, tal y como se afirma en el "Encuentro de Punto de Contacto y Enlaces sustracción internacional, Cartagena de Indias, 15-17 diciembre 2014, en http://www.cumbrejudicial.org/c/document_library/get_file?uuid=c50d1fb9-ee64-464b-bd40 703977886bb2\&groupId=10124 (consultado el 1 de junio de 2018).

59 Vid. E. Rodríguez PinEAu, "La oposición al retorno del menor secuestrado: movimientos en Bruselas y La Haya", REEI, 2018, núm. 35, en http://www.reei.org/

${ }^{60}$ Véase Doc. prél. № 9 de la Comisión Especial "Violence conjugale et familiale et l'article 13 'risque grave' exception dans le fonctionnement de la Convention de La Haye 1980 sur les aspects civils de l'enlèvement International d'enfants: Document de réflexion", https://assets.hcch.net/docs/582a0181-c82c-4398-988d-4e7bf469f9de.pdf (consultado el 27 de junio de 2018).

61 Vid. F. J. Forcada-Miranda, "Carencias, Necesidades y conflictos de la sustracción internacional de menores y el novedoso marco legal español”, REDI, 2016, núm. 68-2, pp. 337-346; ID.,"El nuevo proceso español de restitución o retorno de menores en los supuestos de sustracción internacional: La decidida apuesta por la celeridad y la novedosa Circular de la Fiscalía 6/2015 (Parte I)", Bitácora Millennium DIPr., 2016, núm. 3; ID., "Recent Spanish Developments in International Family Law. International Family Law Journal", 2016, vol. 1, pp. 11-12; ID., Sustracción internacional de menores y mediación familiar, 2015, Madrid, Sepin, D. L.

62 Vid. Doc. Pre. No 3 de junio de 2017, en https://www.hcch.net, (consultado el 20 de mayo de 2018). El objetivo de esta Guía es promover una mayor coherencia en la aplicación e interpretación del art. 13.b), de conformidad con los objetivos del CLH 1980, teniendo en cuenta interpretación, conclusiones y recomendaciones anteriores de las Comisiones Especiales de la Conferencia de La Haya. Particularmente, el documento se divide en tres secciones. La sección 1 se refiere a las circunstancias de la letra b) del apartado 1 del art. 13, que explican las relacionadas con la violencia doméstica y el abuso de menores, junto con lo que puede tener efectos directos e indirectos sobre un niño. La sección 2 trata de otras aseveraciones de este precepto que se relacionan directamente con la situación del niño al regresar. La sección 3 comparte escenarios de casos referidos a las posibilidades del regreso del progenitor con el niño o, cuando se argumenta que dicha situación de devolución es un grave riesgo para el niño o lo coloca en una situación intolerable. 
Oficina permanente de la Conferencia de La Haya ${ }^{63}$. Dicho Proyecto forma parte del trabajo previo a la $7^{a}$ Reunión de la Comisión especial sobre el funcionamiento práctico de los Convenios de La Haya de 1980 y de $1996^{64}$, que tuvo lugar durante octubre de $2017^{65}$.

28. Una de las cuestiones de mayor interés afrontadas en dicho documento es determinar si la violencia de género/doméstica es la ejercida sobre la o el menor o también lo es la practicada contra su madre, a pesar de que directamente no vaya encaminada hacia su prole. La Comisión Permanente de la Conferencia de La Haya parte de consideraciones emitidas por expertos, quienes han observado el daño psicológico que conlleva tanto el maltrato físico y psicológico ejercitado directamente al o la menor, como cuando existe violencia de género en el ámbito familiar ${ }^{66}$. Ahora bien, este organismo declara que no se trata de una presunción automática, pues la violencia sobre la pareja y las secuelas en las o los hijos, y los riesgos futuros asociados deben evaluarse en cada caso concreto a partir de las pruebas aportadas. Sobre este punto, tanto UNICEF ${ }^{67}$ y Save the Children ${ }^{68}$, como un sector de la doctrina ${ }^{69}$ y especialistas afirman que los malos tratos ejercidos sobre la madre perturban negativamente al o la menor en igual medida que los malos tratos ejercidos directamente sobre él o ella. En consecuencia, si esta realidad es asumida, la violencia de género sufrida por la progenitora supondrá un grave riesgo para el regreso de los y de las menores sustraídos en tales situaciones.

29. El documento preliminar de la Guía de Buenas Prácticas sobre la aplicación del art. 13.b) CLH $1980^{70}$ sugiere una lista no exhaustiva de factores y circunstancias, que pueden permitir identifica situaciones de violencia contra los y las menores, teniendo en cuenta que se trata de procesos normalmente expeditivos ${ }^{71}$. Estos factores podrán ser considerados por los jueces a la hora de valorar el grave

63 "The Seventh Meeting of the Special Commission on the Practical Operation of the 1980 Hague Child Abduction Convention and the 1996 Hague Child Protection Convention, October 2017", en https://assets.hcch.net/docs/0a0532b7-d5804e53-8c25-7edab2a94284.pdf. (consultado el 1 de juniode 2018).

${ }^{64} \mathrm{Tal}$ y como podemos comprobar en los trabajos preparatorios de la $7^{\mathrm{a}}$ reunión de la Comisión Especial de octubre de 2017, que se puede consultar en https://assets.hcch.net/docs/0a0532b7-d580-4e53-8c25-7edab2a94284.pdf, donde también hacen alusión a la guía del art. 13.b) del CLH 1980.

65 Véase el web de la Conferencia de La Haya "Violence conjugale et familiale et l'article 13 «risque grave» exception dans le fonctionnement de la Convention de la Haye du 25 octobre 1980 sur les aspects civils de l'enlèvement international d'enfants: document de réflexion", Doc. prél. No 9, établi par le Bureau Permanent, mai 2011 en https://assets.hcch.net/docs/ ce5327cd-aa2c-4341-b94e-6be57062d1c6.pdf (consultado 17 de mayo de 2018).

${ }^{66}$ La guía utiliza los términos violencia doméstica y familiar por ser la definición más utilizada en el ámbito judicial y abarcar toda una gama de comportamientos abusivos dentro de la familia. A menos que se indique lo contrario, la guía utiliza el término "violencia doméstica" o "violencia familiar" en este sentido amplio. Estos términos incluyen, por ejemplo, los abusos físicos, psicológicos y financieros, que pueden ir dirigidos hacia el menor, lo que sería maltrato infantil; y / o hacia la pareja o el cónyuge (a veces referido como "abuso conyugal" o "violencia de pareja") y / a otros miembros de la familia. Puede hacerse una distinción entre la violencia indirecta y directa con respecto a los menores, donde la primera es la violencia doméstica de un padre a la madre $\mathrm{u}$ otros miembros de la familia y que puede afectar al menor, dependiendo de las circunstancias del caso.

${ }^{67}$ La organización UNICEF insiste en que como maltrato se deben considerar "también los efectos indirectos de la violencia familiar sobre los niños, en https://www.unicef.org/lac/Informe_Mundial_Sobre_Violencia_1(1).pdf, p. 69, donde se habla de la exposición a la violencia de pareja en el hogar y efectos en niños.

${ }^{68}$ Véase AA.VV. (2012). Manual de atención para los niños y niñas de mujeres víctimas de violencia de género en el ámbito familiar realizado por Save the Children, https://www.savethechildren.es/publicaciones/ (consultado el 17 de mayo de 2018).

69 Vid. R. LApiedra AlCAmí, "La sustracción internacional de menores: el Convenio de La Haya de 25 de octubre de 1980", en P. Lloria García (DIR.), Secuestros de menores en el ámbito familiar: un estudio interdisciplinar”, 2008, Madrid, Iustel, pp. 189- 218, en esp. p. 215; L.M. Rodríguez Otero, "Menores víctimas de la violencia de género: propuesta de proyecto educativo", Revista internacional de Trabajo social y Ciencias Social, 2013, núm. 6, pp. 71-95; L. CANTERA, Maltrato infantil y violencia familiar de la ocultación a la prevención. Programa de las Naciones Unidas para el Desarrollo en El Salvador, 2002, en http://www.bvsde.paho.org/bvsacd/cd26/maltrato infantil.pdf (consultado el 18 de junio de 2018); A. Ma PÉREZ DEL CAMPo, "Las otras víctimas de la violencia de género", IV Congreso sobre Violencia Doméstica y de Género: Madrid, 16 y 17 de noviembre de 2011, Observatorio contra la Violencia Doméstica y de Género (España), en www.poderjudicial.es/cgpj/ es/temas/violencia doméstica y de género (consultado el 18 de junio de 2018); D. Aguilar Redonda, "La infancia víctima de violencia de género", III Congreso del Observatorio contra la Violencia Doméstica y de Género, Madrid 23 de octubre 2009, en www.poderjudicial.es/cgpj/es/Temas/Violencia doméstica y de género (consultado el 18 de junio de 2018).

${ }^{70}$ Véase Doc. Pre. $\mathrm{N}^{\circ} 3$ de junio de 2017, el Anexo 3 sobre la dinámica de la violencia doméstica, normas internacionales relativas a la violencia doméstica y la violencia contra menores, pp. 115 y ss., en https://www.hcch.net.

${ }^{71}$ Más sobre el tema véase E. Rodríguez Pineau, “La oposición al retorno del menor...”, loc. cit., pp. 8-14. 
riesgo en el retorno y la dinámica de la violencia de género. De gran utilizada es el desarrollo que aparece en la Guía de las pruebas específicas de las que podrá valerse la autoridad requerida en los procesos de sustracción ilícita de menores ${ }^{72}$, tales como, el acceso a la información de acciones judiciales pendientes contra el padre; informes policiales; registros de consulados o embajadas; informes de refugios (casa de acogida) para víctimas de violencia doméstica y certificados médicos relativos a incidentes de violencia; establecimiento de comunicaciones judiciales directas para verifica, por ejemplo, si un tribunal extranjero constató la existencia de esta violencia, si se dictaron órdenes de protección o si hubo acciones judiciales como consecuencia de la constatación de dichas conductas delictivas. Asimismo, podrán acompañarse al proceso los correos electrónicos o cualquier otro tipo de mensajería (whatsApp, mensajes de texto al móvil, redes sociales...) donde se constaten amenazas o el maltrato psicológico hacia la víctima) ${ }^{73}$.

30. No obstante, resulta difícil que la Guía pueda convertirse en la respuesta para salvaguardar a las víctimas de la violencia de género/doméstica y la difícil elección del retorno de las y de los menores sustraídos en dichas circunstancias ${ }^{74}$. En estos asuntos, echamos en falta acciones encaminadas a la reforma del art. 13.1 b) del CLH 1980 para introducir soluciones más sensibles y acordes a los conflictos planteados por la violencia machista. A pesar de ello, lo más significativo es confirmar que la Conferencia de La Haya es consciente de la especial atención que hay que prestar a este tipo de violencia estructural y su incidencia en la sustracción internacional de menores ${ }^{75}$.

31. En el contexto europeo, tras la entrada en vigor del RBr. II bis, la excepción al retorno acogida por el art. 13.1 b) del CLH 1980 es casi inaplicable en situaciones de sustracción de menores entre Estados participantes, al indicarse que la o el menor expuesto a un peligro grave físico/psíquico o situación intolerable debe ser devuelto si se demuestra la adopción de medidas adecuadas (art. 11.4 RBr.II bis). Con la finalidad de procurar soluciones propias que sean acordes al proceso de integración europea ${ }^{76}$, se consagra el principio de retorno inmediato, a pesar de la demostración del grave riesgo que pueda sufrir la o el menor ${ }^{77}$. Ciertamente, en el contexto europeo, la aplicación de la excepción del art. 13.1 b) del CLH 1980 cobra extraordinario interés cuando las y los menores son trasladados ilícitamente a causa de una situación de violencia de género/doméstica, toda vez que el art. $11.4 \mathrm{RBr}$. II bis parece obviar que el secuestro de menores, en no pocas ocasiones, puede venir motivado por estas delicadas circunstancias ${ }^{78}$. Al no tenerlas en cuenta, se facilita en gran medida que la o el menor sea retornado al medio donde se encuentra su exposición al peligro. Para paliar dichas situaciones, el legislador de la UE impone adoptar medidas adecuadas para garantizar la protección de la o del menor una vez tomada la decisión de ser restituido, pero ni las describe ni tampoco indica cuáles deben ser las autoridades encargadas para ello. Pese a la profusión de instrumentos jurídicos y medidas específicas de lucha contra la violencia de género en la $\mathrm{UE}^{79}$, echamos en falta su implementación en materia de sustracción internacional de menores.

${ }^{72}$ Véase Doc. Pre. No 3 de junio de 2017, pp. 76 y ss., en https://www.hcch.net

73 Véase E. Rodríguez PinEAu, "La oposición al retorno del menor secuestrado...,", loc. cit., pp. 9 y ss.

74 Como también afirma H. BALE, "Taking Flight-Domestic Violence and Child...”, loc. cit.

75 Opinión también resaltada E. RodríGuez PinEAu, "La oposición al retorno del menor secuestrado...", loc. cit. pp. 8 y ss.

76 Vid. I. ReIG FABADO, "El traslado ilícito de menores en la unión europea: retorno vs. violencia familiar o doméstica", Cuadernos de Derecho Transnacional, Marzo 2018, Vol. 10, № 1, pp. 610-619, en esp. p. 615; ID., "Incidencia del Reglamento 2201/2003 en materia de sustracción internacional de menores: interacción con el Convenio de La Haya de 1980", en LLORIA GARCíA, P. (COORD.). Secuestro de menores en el ámbito familiar: un estudio interdisciplinar. Madrid. Iustel, 2008, pp. 220-228.

77 Vid. P. McEleavy, "The New Child Abduction Regime in the European Community: Symbiotic Relationship or Forced Partnership?", Journal of Private International Law, 2005, pp. 5-34.

${ }^{78}$ La doctrina ya viene alertando de esta problemática [M. H. WeINER," International Child Abduction and the Escape from Domestic Violence", Fordham Law Review, 2000, vol. 69, pp. 593-706, disponible http://ir.lawnet.fordham.edu/flr/vol69/iss2/6/ (consultado el 7 de junio de 2018); M. KAYE, "The Hague Convention and the flight from domestic violence...", loc. cit., pp. 191-212, aunque faltan estadísticas específicas sobre sustracción internacional de menores y violencia de género. No obstante, si se aprecia un incremento en el ámbito judicial español de casos se alega el no retorno basado en el art. 13.1 b) del CLH 1980 con motivo de la violencia machista sufrida por la progenitora sustractora. Para un estudio de la jurisprudencia española en este sentido véase C. RuIz SutiL, "El enfoque de género en la sustracción internacional de menores", J. Mª GiL RuIz (coord.), El Convenio de Estambul como marco del Derecho antisubordiscriminatorio, Madrid, Edit. Dykinson, 2018, pp. 245-275 (en prensa).

79 Véase el epígrafe número 2 de este trabajo o la obra de J. Ma . GIL RuIz, "Nuevos instrumentos vinculantes para una ciencia de la legislación renovada: Impacto normativo y de género”, Anales de la Cátedra Francisco Suárez, 2013, 47, pp. 15-42. 
32. Como consecuencia de ello, subsisten aspectos negativos que dificultan la localización del interés superior del o de la menor en estas especiales circunstancias, como la ausencia de conexión de la violencia de género con la excepción del grave riesgo del art. 13.1 b) LH $1980^{80}$, la imprecisión de la prueba de la violencia de género ${ }^{81}$ en estos procesos tan sumarísimos y la consideración del hijo o hija como víctima directa de los malos tratos y su impacto en la devolución al país de residencia habitual ${ }^{82}$. Si comprobamos algunas decisiones españolas, como en el Auto de la AP de Barcelona de 23 de abril de $2012^{83}$, dicha Sala se centra en que para fallar la no restitución del o de la menor no basta con una mera referencia a una situación de riesgo o perjuicio si fuese devuelto, sino que ha de ser particularmente probada $^{84}$, a pesar de poder demostrar la violencia de género. En similar sentido, un nutrido grupo de resoluciones dictadas por nuestras autoridades judiciales obligan al retorno del o de la menor sustraído ilícitamente a España, por no considerarlo víctima directa de los malos tratos ocasionados a su progenitora. Esta jurisprudencia, pese a que, por un lado, considera que una situación de violencia de género "crea un clima censurable y negativo que no beneficia a los hijos", y que, "la gravedad de los insultos e injurias del padre hacia la madre puede influir negativamente en el menor", por otro lado, entiende que para demostrar este extremo resulta necesario un estudio psicológico pormenorizado imposible de aportar en estos procesos debido a su celeridad ${ }^{85}$.

80 B. HaLe, "Taking Flight-Domestic Violence and Child Abduction", Current Legal Problems, Volume 70, Issue 1, 1 December 2017, pp. 3-16, https://doi.org/10.1093/clp/cux001, describe una serie de escenarios en los que es posible que se establezca la excepción del art. 13.1.b) cuando se alega violencia de género o doméstica.

81 En el Derecho interno español, la condición de víctima de violencia de género es una de las reformas polémicas que introduce el Real Decreto-ley 9/2018, de 3 de agosto, de medidas urgentes para el desarrollo del Pacto de Estado contra la violencia de género (BOE núm.188, 4 de agosto de 2018), donde el art. 23 de la Ley integral es objeto de modificación con una doble finalidad. Por una parte, para concretar y ampliar los títulos judiciales habilitantes para acreditar la condición de víctima de violencia de género; $y$, por otra parte, para establecer otros títulos no judiciales habilitantes para los casos en los que no hay denuncia y, en consecuencia, tampoco existe procedimiento judicial abierto. La ampliación de los mecanismos de acreditación de las situaciones de violencia de género se basa, entre otras cuestiones, en el art. 18.3 del Convenio de Estambul, que exige no supeditar la protección de las víctimas de violencia de género al ejercicio por parte de aquéllas de acciones legales ni a la declaración contra el autor. Hasta este momento, se operaba con una orden de protección a su favor expedida por el correspondiente Juzgado de Violencia sobre la Mujer o de Primera Instancia e Instrucción) con arreglo al art. 544 ter de la Ley de Enjuiciamiento Criminal; con un Informe del Ministerio Fiscal cuando se indique que existen indicios de que la demandante es víctima de violencia de género; con una sentencia condenatoria; con una resolución judicial de la que se deduzca que la mujer ha sido víctima de violencia de género que concluye el procedimiento penal, archivo de la causa por extinción de la responsabilidad penal por fallecimiento o encontrarse el imputado en paradero desconocido o el sobreseimiento provisional por expulsión del denunciado. Al art. 23 de la Ley integral se le añade el siguiente párrafo: "también podrán acreditarse las situaciones de violencia de género mediante informe de los servicios sociales, de los servicios especializados, o de los servicios de acogida destinados a víctimas de violencia de género de la Administración Pública competente; o por cualquier otro título, siempre que ello esté previsto en las disposiciones normativas de carácter sectorial que regulen el acceso a cada uno de los derechos y recursos".

82 Vid. C. Vaquero López, "Matrimonio y maternidad: cuestiones de derecho internacional privado desde una perspectiva de género", Cuadernos de Derecho Transnacional (Marzo 2018), Vol. 10, № 1, pp. 439-465, esp. pp. 460-465, donde defiende que la solución del litigio con dicha perspectiva plantea un importante problema de prueba, cuya valoración exige una formación específica desde esta óptica.

83 (EDJ 2012/138274, www.elderecholefebvre.com).

${ }^{84}$ Véase el FJ 1, donde finalmente no se demostró el grave riego del o de la menor y se decide su restitución a Inglaterra.

85 Dichos argumentos han sido recogidos en las respuestas otorgadas a las solicitudes de restitución procedentes de Estados vinculados o no por el RBr. II bis, tal y como se puede verificar en la SAP de Alicante de 20 de enero de 2016 (EDJ 2016/91058, www.elderecholefebvre), donde en su FJ 5 se expone que: "la existencia de adveración sobre la denuncia en España de violencia del padre sobre la madre y puesto que todas las denuncias habían sido archivadas" ocasionó que el órgano competente estimara la restitución de los menores a Chile. En la SAP de Málaga, de 30 de abril de 2015 (EDJ 2015/222469, www.elderecholefebvre) se señala en su FJ 2: “...incluso sin desconocer que en el matrimonio constituido entre la demandada (hoy apelante) y su esposo han existido algunos episodios de violencia doméstica, no estima que los mismos sean de la entidad suficiente para impedir el retorno, al no constar que los episodios protagonizados por el padre les afectasen directamente a los menores, todo ello sin desconocer lo negativo que para los menores supone presenciar episodios de violencia en el seno familiar". En la SAP de Baleares, de 9 de mayo de 2016 (EDJ 2016/87715, www.elderecholefebvre) se aportó el expediente de violencia familiar tramitado en un tribunal de Argentina y del que no se pudo inferir el requisito exigido en el art. 13.b) CLH 1980 para justificar la no devolución del o de la menor. La SAP de Las Palmas, de 25 de julio de 2016 (EDJ 2016/297445, www.elderecholefebvre) afirma que la madre es quien tiene la carga de acreditar que, con la restitución del o de la menor a Bélgica, el menor va a sufrir un grave riesgo físico o psíquico o se expondrá a una situación intolerable. No se admite, a priori, que los malos tratos sufridos por la madre sean un riesgo psíquico para el hijo e hija, aunque dichos actos delictivos se hayan ocasionado en presencia del o de la menor (FJ 2). La SAP Las Palmas de 9 febrero de 2017 (EDJ 2017/93957, www.elderecholefebvre), en su FJ 2 dispone que: "aunque 
33. El impacto de la violencia de género en decisiones de retorno tampoco ha sido considerado en la STC (Sala $2^{\mathrm{a}}$ ), de 1 febrero de $2016^{86}$, incluso cuando se había admitido un episodio violento concreto (FJ 3) y donde existían varias denuncias por violencia de género de la madre contra el padre, tanto en España ${ }^{87}$ como en Suiza. En esta oportunidad, el TC optó por acogerse al motivo recogido en el art. 12 del CLH 1980 para fallar el retorno de una menor a Suiza, tras considerar que había quedado integrada en España debido a las dilaciones del procedimiento de restitución ${ }^{88}$. En todo caso, el Alto tribunal ha malgastado una oportunidad única para trazar algunas directrices sobre la incidencia de la violencia de género en la aplicación del art. 13.b) del CLH 1980, al margen de la eventual situación de integración de la hija en nuestro país (FJ 10) ${ }^{89}$. Cierto es que el elemento de integración de la menor en España ha sido concluyente para la decisión de no retorno, teniendo presente que para su interpretación se aplicaba CLH 1996, por ser Suiza el país de residencia habitual anterior de la menor ${ }^{90}$.

34. Como observamos, aún perviven flecos en relación con las decisiones de retorno y la valoración del grave riesgo en los y las menores cuando concurre violencia de género. Este panorama origina un difícil ajuste entre la acreditación de estos hechos delictivos y la alegación del motivo de grave riesgo del o de la menor para su retorno. La falta de interconexión entre ambos extremos ocasiona que las

indirectamente pueda admitirse a priori el riesgo psíquico de la menor de presenciar malos tratos de palabra o de obra sobre su madre, decíamos quién tiene la carga de acreditar dicha excepción es quien la opone y dicha prueba no existe y no existe porque esta Sala no puede convertirse en un órgano penal que determine si efectivamente la madre o la menor ha sufrido daños fisicos, coacciones, injurias o maltrato de palabra y obra que haya repercutido y vayan a seguir repercutiendo a su vez en la integridad psíquica de la hija, aportando una denuncia que no consta haya prosperado en Letonia y todo ello obviamente sin perjuicio de lo que puedan adoptar las autoridades judiciales letonas tanto en el ámbito penal como en el ámbito civil en el que deberá resolverse si concurren o no circunstancias que justifiquen el cambio de domicilio". En la Sentencia núm. 754/16 del juzgado núm. 3 de Primera instancia de Granada, de 14 de diciembre de 2016 y en la posterior SAP de Granada núm. 152/2017, de 21 de abril de 2017 (resoluciones facilitadas por la amabilidad de Francisca Granados, Asesora del Centro de la Mujer de Maracena, en Granada), se condena a la inmediata restitución a Italia de los hijos menores sustraídos, a pesar de probar la violencia de género mediante una sentencia penal española. Dicha situación se argumenta en la resolución de primera instancia en los siguientes términos: “...entre los progenitores existen episodios de violencia de género, pero que no consta que afectasen directamente a los hijos, todo ello sin desconocer lo negativo que para los menores supone presencias la violencia en el seno familiar" (FJ 2).

${ }^{86}$ (EDJ 2016/2237, www.elderecholefebvre). El Auto recurrido descarta la existencia de riesgo para la menor de forma imprecisa, sin concretar los datos en que se basa, aunque entrar a valorar hechos pendientes ante el Juzgado de Violencia contra la Mujer, donde el padre de la menor está imputado y ha reconocido los malos tratos. Dicha resolución es comentada particularmente C. M. CAAmiña Domínguez, "El interés superior del menor: la integración en el nuevo medio", Cuadernos de Derecho Transnacional, 2016, vol. 8, No 2, 77-91.

87 Ante las denuncias formuladas por la madre contra el padre por violencia de género, el Juzgado de Violencia contra la mujer es el órgano competente por los malos tratos cometidos en España.

${ }^{88}$ FJ 10, el TC reconoce que, “...el procedimiento se promueve trascurridos apenas tres meses desde que tuvo lugar el hecho que le da origen. Su definitiva terminación, sin embargo, hasta la resolución del recurso de apelación, se retrasa a abril de 2015, lo que supone que desde los hechos acaecidos en agosto de 2013 hasta la finalización del procedimiento han trascurrido casi veinte meses. En este prolongado periodo de tiempo, y sin olvidar la corta edad con que cuenta la menor (seis años en la actualidad), resulta patente que ha podido producirse una plena integración de la niña en su nuevo medio, lo que es necesario, en todo caso, valorar, a fin de hacer efectivo el principio de superior interés de la menor. En consecuencia, la situación de integración de la menor, por exigencia del principio de interés superior de la misma, imponía una valoración, omitida en la resolución impugnada, que ponderase el conjunto de circunstancias como la edad, el entorno y la convivencia habitual, incrementada con la presencia de un nuevo miembro en el contexto familiar y la escolarización desde el año 2013 de la niña en España, lo que genera el reconocimiento de la insuficiencia de motivación en la resolución impugnada que es inherente al contenido constitucional del art. 24.1 CE"'.

${ }^{89}$ Aunque no proceda valorar la integración del o de la menor en el procedimiento de restitución sustanciado en el ámbito del CLH de 1980, al no haber transcurrido el mencionado plazo de un año en el sentido de su art. 12, no significa que dicha integración no merezca ser tomada en consideración en el ámbito de otro procedimiento. Así, con independencia de las causas de la falta de celeridad, no cabe negar que la permanencia del o de la menor en el país de la sustracción durante ese tiempo puede estar provocando su integración en dicho país.

${ }^{90}$ Hay que tener presente que según el art. 7.b) CLH 1996, el período de un año empieza a contar a partir de la fecha en que la persona, institución u organismo que tenga los derechos de guarda conozca o debiera haber conocido el paradero del niño. En su caso, si fuese aplicable el art. 12.2 CLH 1980, la fecha en la que se produjo la sustracción es la que empieza a contar para que trascurra el plazo de un año y no ordenar la restitución si se demuestra que el niño está integrado en su nuevo ámbito. Sobre el tema, véase P. LAGARDE, Informe explicativo del CLH 1996. Texto adoptado por la XVIII Sesión, Oficina permanente de la Conferencia de La Haya, Holanda, 1996. Para jurisprudencia y comentario respecto de la interpretación del término "integrado" en el art. 12(2) CLH 1980, véase la Base de Datos sobre Sustracción de Niños - INCADAT: www.incadat.com. 
autoridades judiciales, en raras ocasiones, emitan una decisión de no restitución. De hecho, la solución mayoritaria otorgada por los jueces españoles se ajusta al retorno inmediato, tal y como ordenan los instrumentos internacionales, sin abordar una respuesta implementada en relación a la violencia machista. Desde el ámbito jurisprudencial, echamos en falta un análisis más reposado de cómo debe admitirse en dichos procedimientos la existencia de violencia machista y su repercusión en los hijos e hijas y asegurar una resolución que garantice un entorno "libre de violencia".

\section{Aspectos relevantes del Texto de Refundición en el tratamiento de la sustracción internacional de menores y la violencia de género}

35. El capítulo III del Texto de Refundición dedica una sección específica para la situación de las y de los niños que han sido sustraídos ilícitamente (arts. 21 a 26 del Texto de Refundición). Nos llama la atención que dicha normativa entre a detallar, sobre todo, los aspectos procesales de la sustracción internacional y el retorno. Entre las nuevas obligaciones destacan la concentración de la competencia en los casos de sustracción de menores en un número limitado de tribunales, acompañada de una especialización ${ }^{91}$; la posibilidad de recurrir una sola vez la orden de restitución (art. 25.4); la previsión de un período máximo de 18 semanas en todas las fases de la sustracción internacional (arts. 23.1), incluida la fase de ejecución (art. 32.4) ${ }^{92}$; la invitación de manera explícita a que el juez examine si una orden de restitución debe declararse provisionalmente ejecutable, sin perjuicio del cualquier posible recurso, teniendo en cuenta el interés del o de la menor (art. 25.3) o la promoción del recurso a la mediación, vigilando que esta vía alternativa de solución de controversias no se convierta en un elemento dilatorio del proceso (art. 23.2). La última Resolución legislativa del Parlamento sobre el Texto de Refundición de 18 de enero de 2018 añade el apartado 5 bis al art. 25 para requerir al juez que haya ordenado la decisión de retorno que la comunique a la autoridad central del Estado miembro de residencia habitual, así como la fecha en la que surtirá efecto.

36. En cualquier caso, en este epígrafe prestaremos atención a varias modificaciones introducidas para sopesar su influenci en el tratamiento de las sustracciones de menores en contexto de violencia de género y el grave riesgo de su retorno al país de la residencia habitual.

37. En primer lugar, si comparamos las correcciones impuestas por el Texto de Refundición a la aplicación del art. 13.b) del CLH 1980, evidenciamos que la nueva formulación del art. 25 mantiene una respuesta similar al vigente 11.4 RBr. II bis. Al mantener el mecanismo generalizado del retorno inmediato, se sigue sin atender debidamente a las situaciones de violencia de género ${ }^{93}$. La doctrina viene sosteniendo que para responder de forma más adecuada se debería incluir una referencia expresa a la violencia de género/doméstica o, en su caso, establecer la imposibilidad de retornar cuando la sustracción venga originada por la violencia machista ${ }^{94}$, planteamientos que de momento no han sido incorporados en el art. 25 Texto de Refundición. Únicamente, este precepto se dedica a reforzar la cooperación

91 Tal y como prevé el considerando 26 del nuevo texto. Según E. Rodríguez Pineau, "Refundición del Reglamento Bruselas II bis; de nuevo sobre la función del Derecho internacional privado europeo", REDI, 2017, núm.1, vol. 69, pp. 139-165, en esp. p. 143, nota 11, la especialización de los juzgados deriva de la Guía de Buenas Prácticas del CLH 1980 del año 2003 y que el actual art. 778 quarter (2) de la LEC viene a confirmarlo

92 Según el considerando 27 del nuevo texto, cuando las autoridades centrales inicien o faciliten el inicio de procedimientos judiciales para la restitución de un menor, deberán garantizar que el expediente elaborado para tales procedimientos se complete en un plazo de seis semanas, salvo que existan circunstancias excepcionales que lo hagan imposible. A fin de permitir a la autoridad central requerida cumplir este plazo, la autoridad central requirente deberá ponerse en estrecho contacto con el solicitante y responder sin demora a cualquier solicitud de información adicional o documentos que falten procedentes de la autoridad central requerida.

93 La doctrina viene criticando en similar sentido el vigente art. 11.4 RBR. II bis. Vid. K. Trimmings, Child Abduction within the European Union, Oxford, Hart Publishing, 2013, p. 144.

94 Véase K. Trimmings, Child Abduction..., op. cit., pp. 149-155. M. Requejo Isidro, "Secuestro de menores y violencia de género en la Unión Europea”, Anuario Español de Derecho Internacional Privado, vol. 6, 2006, pp. 179-194, pp. 190-192, en esp. p. 194 sostiene que la redacción del art. 11.4 del RBr. II bis permite superar la debilidadde los undertakings al ofrecer también medidas de protección al progenitor sustractor que ha huido de laviolencia. 
internacional entre autoridades, particularmente la adopción de las medidas cautelares o provisionales y en el derecho a oír la opinión del o de la menor en dicho procedimiento.

38. Ahora bien, si el legislador de la UE decidiera a afrontar la violencia de género en la regulación de la sustracción internacional de menores, tal y como requiere el Convenio de Estambul, una de la posibles modificaciones se encaminaría a que las autoridades de la residencia habitual de la o del menor puedan declinar su competencia a favor de las autoridades del Estado donde se halle retenido ilícitamente, dada la vulnerabilidad de las víctimas para afrontar un regreso al país donde se encuentra el presunto agresor $^{95}$. Evidentemente, esta solución excepcionaría las reglas contempladas en el CLH 1980 y en el actual RBr. II bis, en las que únicamente resulta competente la autoridad de origen de la residencia habitual para cualquier aspecto derivado de la responsabilidad parental. En este sentido, es interesante el punto de vista del Juez canadiense Chamberland que apuesta por el aplazamiento de la restitución hasta que las autoridades de la residencia habitual se pronuncien sobre la custodia ${ }^{96}$, siempre se logre acreditar que la huida al extranjero fue motivada por la violencia de género.

39. La apuesta por la transferencia de la competencia en situaciones difíciles aparece recogida en el considerando 18 de la Resolución legislativa del Parlamento Europeo, de 18 de enero de 2018, sobre el Texto de Refundición, donde se insiste en que "Merece una atención especial el hecho de que, en casos excepcionales, como los casos de violencia doméstica o de género, las autoridades del Estado miembro de la residencia habitual del menor pueden no ser la autoridad más apropiada para conocer del asunto. La autoridad competente, con carácter excepcional y en condiciones determinadas, puede remitir el asunto a la autoridad de otro Estado miembro que esté mejor situada para conocer el asunto. Ahora bien, en este caso se debe recabar en primer lugar la aprobación de la autoridad a la que se remitió la competencia, ya que, una vez que ha aceptado examinar el asunto, no puede remitirla a su vez a una tercera autoridad. Antes de proceder a una transferencia de competencia, es fundamental examinar y tener plenamente en cuenta el interés superior del menor...". Si finalmente este considerando quedase aprobado en dichos términos, resultaría una postura firme por parte de la Unión en implementar la problemática de la violencia de género/doméstica en el instrumento europeo de referencia en materia de familia y menores. Lo cierto es que la violencia de género o doméstica todavía no se contemplan en los articulados relativos a la competencia judicial de la responsabilidad parental (art. 7 del Texto de Refundición) ni en los de sustracción internacional (art. 25 y siguientes del Texto de Refundición). La dificultad para la aprobación de este tipo correcciones deriva del importante cambio que supondría la orientación conceptual del CLH 1980 y, sobre todo, la excepción al principio de confianza entre Estados miembros en beneficio del interés del o de la menor en escenarios de violencia de género

40. En segundo lugar, otro de los aspectos relevantes es el derecho del niño o niña a ser oído ${ }^{97}$, que implica escuchar sus deseos, sentimientos y opiniones para que sean valorados en el contexto de una decisión de retorno al país de origen ${ }^{98}$. El actual art. 11.2 RBr. II bis dispone que los tribunales pueden dar audiencia a la persona menor durante el proceso en caso de aplicarse los art. 12 y 13 del CLH 1980, a menos que no se considere conveniente, habida cuenta de su edad o grado de madurez. En el Texto de

95 Vid. M. H. Weiner," International Child Abduction and the Escape from Domestic Violence", Fordham Law Review, 2000, vol. 69, pp. 593-706, disponible http://ir.lawnet.fordham.edu/flr/vol69/iss2/6/ (consultado el 7 de junio de 2018).

96 Vid. J. Chamberland, "Violencia doméstica y sustracción internacional de niños: algunas pautas de reflexión. Enfoque especial: el Convenio de La Haya de 19 de octubre de 1996 relativo a la competencia, la ley aplicable, el reconocimiento, la ejecución y la cooperación en materia de responsabilidad parental y de medidas de protección de los niños", Boletín de los Jueces, vol. X, 2005, pp. 42-47.

97 El art. 12 de la Convención de las Naciones Unidas sobre los Derechos del Niño; el art. 3, art. 6 b), párrafo segundo de la Convención Europea sobre el Ejercicio de los Derechos de los Niños; el art. 11.2 del RBr. II bis, entre otros articulados, han establecido una obligación de analizar los deseos y sentimientos del niño y tomarlos debidamente en cuenta en ciertos procesos judiciales relacionados con el niño, considerando la edad y la madurez del niño.

98 Cuestión ya manifestada por HCCH, Guía de buenas prácticas en virtud del Convenio de La Haya de 25 de octubre de 1980 sobre los Aspectos Civiles de la Sustracción Internacional de Menores. Cuarta parte-Ejecución, 2010, pp. 31-34, en https://www.hcch.net/es/publications-and-studies/publications2/guides-to-good-practice. 
Refundición, la audiencia se refuerza con las modificaciones previstas en los arts. 20 y 24 , donde se distingue entre dar la oportunidad de ser oído (en condiciones de formarse un juicio propio y expresar sus propias opiniones) y la importancia que debe dar el juez a la opinión de los o de las menores, en atención a su edad y madurez. Ambos aspectos deben consignarse tanto en la resolución, como en su certificado anejo de ejecutividad (art. 53.5), de manera que la autoridad que haya instado el reconocimiento de una resolución dictada en otro Estado miembro no podrá negarse a reconocerla por el mero hecho de que la audiencia del o de la menor no se formalizara conforme sus propias normas procesales ${ }^{99}$.

41. En este sentido, el Considerando 19 del Texto de Refundición recomienda que en la exploración del o de la menor sea efectuada por profesionales cualificados, que posean la capacitación y los conocimientos especializados adecuados y su alcance en los procedimientos de restitución internacional, a fin de detectar indicios de traumatismo o posible manipulación o represalias ${ }^{100}$. Dicha especialización debe alcanzar a la valoración del grave riesgo en la devolución cuando consta la existencia de una situación de violencia de género. Desde nuestro punto de vista, el dictamen pericial que puede exigir el juez español conforme al art. 299.1 párrafo 4 de la Ley de Enjuiciamiento Civil a la hora de resolver el retorno en estas delicadas circunstancias, podría ser realizado por los equipos especialistas e interdisciplinares en violencia de género, con la finalidad de valorar su alcance en dicha decisión, al margen de si se entrar a enjuiciar ante nuestra autoridades el delito de violencia de género. La invocación del art. 13.1 b) del CLH 1980 en estos especiales entornos debe conducir a tener en cuenta la seguridad y el bienestar de la persona menor ${ }^{101}$.

42. En tercer lugar, tenemos que ocuparnos del "mecanismo de última palabra o segunda instancia" y el impacto nocivo que ocasiona a los casos de sustracciones internacionales motivados por la violencia de género. Actualmente, la autoridad del Estado de origen puede revisar la decisión de no devolución de la o del menor (apartados 6 a 8 del art. $11 \mathrm{RBr}$. II bis), sistema que viene siendo muy cuestionado $^{102}$. Tal y como viene denunciando un sector doctrinal español ${ }^{103}$, este tipo de respuestas articuladas en la normativa de la UE son fruto de la consecución de determinados fines comunitarios, aventurando la consecución del interés superior del o de la menor. La propuesta de refundición del RBr. II bis introduce algunas mejoras dicho mecanismo de segunda instancia ${ }^{104}$. Entre ellas, facilitar la comunicación entre las autoridades implicadas, incluso a través de las autoridades centrales y la Red judicial europea (art. 26.2 del Texto de Refundición). También obliga a la traducción de la resolución adoptada por la autoridad que deniega la restitución (art. 26.2 del Texto de Refundición), debiendo especificar el motivo de excepción del CLH 1980 en el que se fundamenta la resolución de no retorno (art. 26.1 del Texto de Refundición).

99 Tal y como señala la propuesta de Reglamento Br. II bis COM (2016) 411 final, pp. 4 y 5, donde se reconoce que en este aspecto surgen difícultades por el hecho de que los Estados miembros disponen de normas divergentes que regulan la audiencia del menor.

${ }^{100}$ Conclusiones y Recomendaciones de la Sexta Reunión de la Comisión Especial de la Conferencia de La Haya, Doc. Pre. No 14 de noviembre de 2011 a la atención al funcionamiento práctico del Convenio de La Haya de 1980 sobre Sustracción Internacional de Menores y del Convenio de La Haya de 1996 sobre Protección de Niños, en https://www.hcch.net.

101 El Proyecto de Guía de Buenas Prácticas sobre el art. 13.b) CLH 1980 recomienda que el menor sea entrevistado por individuos con la capacitación y los conocimientos especializados adecuados para escuchar a menores, ya sea un juez, un perito u otra persona y, de ser posible, con conocimientos y entendimiento del alcance de los procedimientos de restitución y debería también tener conocimientos especializados en la materia de alegación del grave riesgo, como por ejemplo en violencia de género y sus efectos en los niños. Véase Doc. Pre. No 3 de junio de 2017, pp. 50 y 51, en https://www.hcch.net.

102 Tal y como expone E. Rodríguez Pineau, "La oposición al retorno del menor...” loc. cit., pp. 17-19. Al respecto del proceso de elaboración de este mecanismo y la falta de fundamento de las medidas adoptadas puede verse K. Trimmings, Child Abduction..., op. cit., pp. 25-69; en lo relativo a la efectividad del mecanismo, muy críticos P. Beaumont, L. Walker, J. HoLLIDAY, "Conflicts of EU Courts on Child Abduction: The reality of Article 11(6)-(8) proceedings across the EU", Journal of Private International Law, 2016, vol.12, pp. 211-260.

103 Vid. Rodríguez Pineau, E. (2004). El nuevo Reglamento Comunitario sobre litigios matrimoniales y responsabilidad parental. Diario La Ley, n ${ }^{\circ}$ 5944, año XXV, 30 enero, Ref. ${ }^{\circ}$ D- 25, pp. 1 - 18, p. 3, en http://www.laley.net.

104 Estos términos aparecen en E. Rodríguez PinEau, "La refundición del Reglamento..., op. cit., p. 145; ID., "La oposición al retorno del menor...", loc. cit., pp. 21-22. 
43. El Estado de la residencia habitual del menor, por su parte, que examina la custodia teniendo en cuenta el interés superior de las o de los menores ${ }^{105}$, si recibe las reclamaciones oportunas dentro del plazo fijado, deberá también argumentar las razones y las pruebas en las que se fundamentó la originaria resolución de denegación del retorno emitida por la autoridad requerida (art. 26.4 del Texto de Refundición). Una vez dictada la resolución sobre custodia y que ordene la restitución del menor, ésta será ejecutiva de acuerdo con la sección 4 del Capítulo III, con el fin de garantizar la inmediata restitución del menor ${ }^{106}$, sin necesidad de pronunciamiento jurisdiccional para ello (art. 26.4 último inciso del Texto Refundido), salvo la emisión del certificado correspondiente del art. 53.6 del Texto de Refundición ${ }^{107}$. Esto puede ocasionar un cierto desconcierto a la autoridad del Estado requerido que decide no restituir a la o al menor por ser expuesto a una situación de grave riesgo motivada por la violencia de género. Dicha autoridad quedará obligada a ejecutar la última resolución de retorno y devolver al menor al país de su residencia habitual. No obstante, es posible abrir una vía de oposición a la ejecución de dicha resolución de retorno en el Estado requerido, si concurre alguno de los motivos contemplados en el art. 38.1, apartados d) y f) del Texto de Refundición ${ }^{108}$, como cuando la ejecución de la decisión de retorno fuese incompatibles con otra resolución dictada con posterioridad en el Estado requerido ${ }^{109}$, como podría ser el caso de recaer una sentencia basada en violencia machista.

44. El sistema de oposición a la ejecución es aún más detallado y ampliado en el art. 40.2 del Texto de Refundición ${ }^{110}$, que otorga la vía del rechazo al retorno cuando sea contrario al orden público del Estado miembro donde se halle el menor, siempre que se base en una de las siguientes razones: " a) el menor, con edad y madurez suficiente, se opone a tal punto a la resolución, que la ejecución sería manifiestamente incompatible con el interés superior del menor; b) desde el momento en que se dictó la resolución, otras circunstancias han cambiado de tal manera que su ejecución sería manifiestamente incompatible con el interés superior del niño", como por ejemplo una enfermedad grave sobrevenida de la persona menor o si recayera una sentencia de violencia machista y se la coloca una situación intolerable ${ }^{111}$. Ahora bien, si la denegación de la ejecución se fundamenta en las objeciones de la o el menor al regreso, las autoridades competentes del Estado miembro de ejecución deberán adoptar todas las medidas pertinentes destinadas a prepararlo para su vuelta al país de origen. Para ello, se establece la

\footnotetext{
105 Véase el considerando 30.

106 Véase la STJUE de 1 de julio de 2010, en el Asunto C-211/10 PPU. D. Povse contra M. Alpago (ECLU: EU: C-2010:400, http://curia.europa.eu), donde se aclara que, entre otras cuestiones, para que una resolución dictada en virtud del apartado 8 del art. 11 resulte ejecutiva en relación con la restitución de un menor no es necesario que haya procedimientos incoados sobre la custodia del menor ante el órgano jurisdiccional de origen. El art. 40 del RBr. II bis establece la aplicación de la Sección 4 "a la restitución de un menor a tenor de una resolución judicial que requiera dicha restitución, con arreglo al aparatado 8 del art. 11". La fuerza ejecutiva se extiende a la restitución del menor y se produce cuando el órgano judicial del Estado de origen extiende el correspondiente certificado, contenido en el anexo VII del Reglamento 2201/2003, que viene a legitimar la extensión de los efectos de una decisión nacional en los demás Estados comunitarios al margen de un procedimiento de execuátur. Lo que circula por el territorio es el certificado de la decisión y no la decisión en sí misma. Ello significa que la parte que invoque la ejecución de la resolución deba presentar, junto al certificado, copia de la resolución que demuestre que la misma reúne los requisitos necesarios para determinar su autenticidad. Asimismo se acompañarán, siempre que hayan sido necesarias, las medidas adoptadas por el órgano jurisdiccional o por las autoridades para garantizar la protección del menor tras su regreso al Estado de la residencia habitual.

107 Véase el considerando 23 del RBr.II bis.

108 Motivo ya existente en el actual art. 47.2 último inciso del RBr.II bis.

109 En relación con la sustracción internacional de menores resulta especialmente interesante la STEDH de 24 de abril de 2003, asunto Silvestre contra Austria (EDJ 2003/7765, www.elderecholefebvre), que analiza un supuesto en el que el considerable lapso de tiempo transcurrido desde que se produjo el desplazamiento ilícito ha supuesto para la menor un cambio relevante de circunstancias, al haber perdido todo contacto con el padre, mientras que sus lazos con la madre y parientes maternos se han fortalecido. Así, el retorno de la menor la expondría a serios daños psicológicos. El TEDH admite que un cambio en los hechos puede justificar excepcionalmente la no ejecución de una orden de retorno definitiva. Sin embargo, llama la atención que ese cambio no debe derivar de la ineficacia o dilatación de la administración de justicia del Estado a la hora de adoptar las medidas para facilitar la ejecución de la orden de retorno.

110 Véase el considerando 37 de la propuesta del texto refundido.

${ }^{111}$ Con la actual legislación, el TJUE, en el Asunto C 211/10 PPU, D. Povse y M. Alpago, ECLU: EU: C-2010:400, párrafos 80-83, en http://curia.europa.eu, excluye la consideración de alegación de circunstancias sobrevenidas ante el juez del Estado requerido, permitiendo tal posibilidad solo ante el juez del Estado de origen.
} 
cooperación entre las partes implicadas antes de denegar la ejecución, tal y como establece el art. 40.3 del Texto de Refundición.

45. Por consiguiente, comprobamos que el Texto de Refundición corrige el automatismo actual de ejecución de la decisión última de retorno cuando dicha ejecución vaya en contra del interés superior de la o del menor ${ }^{112}$, con el riesgo de incrementar la desconfianza de los Estado miembros ante este tipo de soluciones y aumentar los plazos para el regreso de la o del menor.

46. En definitiva, existen varias propuestas establecidas en el Texto de Refundición que van a tener una repercusión en el tratamiento de las sustracciones de menores en contexto de violencia de género. Pese a ello, echamos en falta una verdadera implementación del Convenio de Estambul en las modificaciones del Texto de Refundición para hacer frente a la violencia machista, propuestas que dejan sin resolver cómo garantizar que una confianza impuesta 'desde arriba' en la cooperación entre autoridades y que sea trasladada a la protección efectiva de la o del menor sustraído ${ }^{113}$.

\section{El retorno seguro y la violencia de género en el contexto europeo}

\section{La "restitución segura" ante la violencia de género}

47. Con el término restitución segura nos referimos a los supuestos en los que la o el menor acabe retornando cuando se alegue la excepción de grave riesgo del art. 13.1.b) del CLH 1980. A tal fin, deben establecerse medidas de seguridad y prevención para que el regreso se produzca sin exponerlo a situaciones de riesgo ${ }^{114}$, como las derivadas de la violencia de género o doméstica.

48. Tanto el actual art. 11.4 del RBr. II bis como el art. 25 del Texto de Refundición impiden que el Estado requerido resuelva con una decisión de no devolución, a pesar del grave riesgo, siempre que se hubieran adoptado las medidas adecuadas para garantizar el regreso del menor o de la menor al Estado miembro requirente. Al poner el acento en la adopción de medidas para asegurar el retorno, restringiendo el funcionamiento el art. 13.1.b) CLH $1980^{115}$, las soluciones deberían enfocarse desde este aspecto. Sin embargo, no se describen ni qué tipo de medidas, ni qué autoridad compete las adoptaría y las controlaría, ni cómo se articula un procedimiento a seguir ${ }^{116}$.

112 Vid. E. Rodríguez Pineau, "La refundición del Reglamento...”, op. cit., p. 151 y 152.

113 Compartimos la opinión de E. Rodríguez Pineau. "La oposición al retorno del menor...”, loc. cit., pp. 26 y 27.

114 Véase I. REIG FABADO, "El traslado ilícito de menores en la Unión...”, p. 616, que entra a analizar las medidas de retorno seguro en el ámbito de aplicación del CLH 1996.

115 BARNETT, A., "Eight Letters...”, cit. p. 9

116 Véase J. HollidAy, "The Rights of the Child. Amending Brussels IIa”, International Family Law, 2015, pp. 38-39, p. 39, que plantea la posibilidad de utilizar medidas como las previstas en el art. 11 del Convenio de La Haya de 1996, solución que también sostiene H. VAN LoON, “The Brussels IIa Regulation: towards a review?", Cross-border activities in the EU- Making life easier for citizens, Workshop for the JURI Committee, 2015, pp. 178-207, en especial 294 y 197, http://www.europarl.europa.eu/RegData/etudes/STUD/2015/510003/IPOL STU(2015)510003 EN.pdf. En todo caso, la falta de medidas adecuadas en los procesos de restitución ya ha empezado a ser apreciada por la STEDH núm. 1437/09 de 12 de julio de 2011, en el asunto Sneersone y Kampanella contra Italia (disponible en HUDOC Case-Law Search en http://hudoc.echr.coe.int/eng?i=002-436, consultado el 22 de mayo de 2018). La cuestión principal versaba específicamente sobre las denominadas «medidas adecuadas» a efectos del art. 11.4 RBr. II bis, que se consideraron insuficientes por parte del tribunal letón que dictó el retorno. El TEDH observa que las distintas sentencias de los tribunales italianos en relación a la custodia solicitada por el padre han fracasado en apreciar y atender a los riesgos identificados por las autoridades letonas en caso de que se produjera la restitución del menor. Los tribunales italianos nunca se refirieron a los daños potenciales de la salud psíquica de menor si fuese devuelto, perjuicios que fueron identificados en los pertinentes informes periciales. Por otra parte, la vivienda propuesta por el padre en Italia no ha sido inspeccionada ni por los tribunales italianos ni por otro tipo de autoridad o persona para asegurarse de que era un hogar adecuado para un niño pequeño. Todo esto hace pensar al TEDH que los tribunales italianos no cumplieron con una correcta evaluación de las dificultades que el menor podría encontrarse en Italia. Por tanto, el TEDH consideró que en la decisión italiana de retorno hubo una falta de motivación, por lo que violaba el art. 8 del CEDH. En todo caso, el TEDH ha establecido que, una vez que se haya constatado la ilicitud del traslado, las autoridades de un Estado parte del CLH 1980 tienen el deber de 
49. La única referencia a las posibles medidas de regreso viene contemplada en la Guía práctica de aplicación del RBr. II bis ${ }^{117}$, donde se indica que deben formalizarse con carácter previo, sin ser suficiente la simple enunciación genérica de las mismas, pudiendo recabar ayuda de la autoridad central del Estado de origen ${ }^{118}$ para comprobar su veracidad y el alcance protector en el Estado requirente.

50. Desde el punto de vista práctico, dichas medidas de protección necesitan el apoyo tanto de las autoridades del Estado de origen como las del país de destino, tal y como ya se recoge en el art. 25 del nuevo Texto de Refundición, a fin de optimizar la efectividad del retorno del o de la menor. Asimismo, sigue siendo posible los compromisos (undertakings) ${ }^{119}$ realizados por las partes para que el regreso sea más eficaz y satisfaga la finalidad de protección de la persona men ${ }^{120}$.

51. El enfoque completo para formalizar un regreso seguro es atender también la posición de la progenitora maltratada que secuestra a sus hijos e hijas para huir de la violencia ${ }^{121}$. A menudo, la articulación de medidas adecuadas para el regreso seguro de todas las víctimas demuestra ser esencial para convencer a la madre, constituyendo una solución válida cuando el Estado requirente trate la cuestión de la violencia de género con un nivel "similar" de protección al del Estado requerido. No obstante, esta vía puede llegar a ser inapropiada, dado el carácter de especial vulnerabilidad de la víctima en relación a la intimidación a la que se puede ver sometida, sobre todo cuando el presunto maltratador tiene la (merecida) reputación de no respetar las órdenes de los tribunales ${ }^{122}$. Asimismo, existe un debate doctrinal sobre el alcance de las medidas para el retorno cuando comprendan la protección de la progenitora sustractora en casos de violencia de género, porque el Reglamento únicamente las enfoca para la persona menor ${ }^{123}$. Incluso se cuestiona algunas de ellas, como el otorgamiento de una vivienda de acogida para garantizar un retorno libre de violencia de género, ya que surge la duda de si ello se ajusta al ámbito civil del $\mathrm{RBr}$. II bis ${ }^{124}$. En todo caso, recordemos que estas medidas pervivirán hasta que el órgano jurisdiccional competente en materia de responsabilidad parental concrete las definitivas (art. 25.5 del Texto de refundición). Lo cierto es que descubrir qué medidas de protección están disponibles en el Estado de origen y

emplear los medios adecuados y efectivos para asegurar la restitución del menor. Su incumplimiento constituye una violación del art. 8 (respeto de la vida familiar) del Convenio Europeo de Derechos Humanos.

117 Véase Comisión Europea, La Guía práctica para la aplicación del Reglamento Bruselas II bis, 2013, pp. 48-49, en file:///C:/Users/ACER1/Downloads/brussels_ii_practice_guide_es(3).pd_(consultada el 20 de junio de 2018).

118 En todo caso, el marco normativo actual, la implentación de estas medidas en el Estado de retorno queda garantizada en el art. 55, apartado b) RBr. II bis en relación a la cooperación internacional para los casos de responsabilidad parental.

119 En este sentido, vid. C. GonzÁlez BeIlfuss, "La regulación comunitaria de la sustracción internacional de menores", VVAA, Los Tratados de Roma en su cincuenta aniversario. Perspectivas desde la Asociación Española de Profesores de Derecho Internacional y Relaciones Internacionales, Madrid, Marcial Pons, 2008, pp. 640-653, esp. p. 646; ibídem, "Nota" a la SAAP Baleares de 23 de abril de 2003, REDI, vol. 56, n 1, 2004, p. 359. P. JimÉNEz BlANCo, Litigios sobre la custodia ..., op. cit., p. 91, sostiene que la adopción de este “undertaking” presupone un grado de desconfianza en las autoridades del Estado de origen que no se compadece con los principios de Derecho comunitario.

120 M. KAYE, "The Hague Convention and the Flight from Domestic Violence...", loc. cit., pp. 198-202. Por el contrario, P. RIPLEY, "A Defence of the Established Approach to the Grave Risk Exception in the Hague Abduction Convention", Journal of Private International Law, vol. 4, 2008, pp. 443-477, en esp. pp. 464-465, sostiene que una interpretación estricta del art. 13.1.b) sigue siendo necesaria, aunque tal vez sea preciso reforzar el sistema de ejecución de las medidas adoptadas para proteger al menor que es devuelto a su Estado de origen, en particular incorporando medidas de protección al progenitor que no desea volver, así como el papel de la Autoridad Central conforme al art. 7(h) del Convenio. También M. ReQueJo IsIDRo, "Secuestro de menores y violencia de género...", loc. cit., pp. 190-192, propone mantener la interpretación estricta del art. 13.1. b) pero ofrece como alternativa para los casos de violencia familiar la vía del art. $20 \mathrm{CH} 1980$.

${ }^{121}$ C. Bruch, "The Unmet Needs of Domestic Violence Victims and their Children in Hague Child Abduction Convention Cases", Family Law Quarterly, 2004, vol. 38, pp. 529-545, 535.

122 Vid. J. Chamberland, "Violencia doméstica y sustracción internacional de niños: algunas pautas de reflexión...", loc. cit., pp. 42-47.

${ }_{123}$ P. Beaumont, L. Walker, J. Holliday, "Parental responsibility and international child abduction in the proposed recast of Brussels IIa Regulation and the effect of Brexit on future child abduction proceedings", International Family Law Journal, 2016, pp. 307-318, en esp. p. 314, entienden que podría salvarse esta limitación interpretando de manera generosa el considerando 29 al entender que las medidas que se adoptan sobre el menor incluyen también al progenitor.

124 P. Weller, "Die Reform der EuEheVO", IPrax, 2017, pp. 222-231, p. 226 
si serán efectivas una vez haya regresado la progenitora y su prole mejoraría la tarea de las autoridades implicadas en el retorno seguro ${ }^{125}$.

52. La legislación española tampoco tiene una respuesta para la adopción de medidas de regreso de menores sustraídos y expuestos a la violencia de género. Una solución sería acudir al actual art. 158, apartado 4, 5 y 6 del Código civil, reformado por la Ley 8/2015 de protección de la infancia y adolescencia, ya que se podrán otorgar medidas dentro de cualquier proceso civil o penal o bien en un expediente de jurisdicción voluntaria. La actuación al amparo del este precepto debe regirse bajo los criterios del interés del o de la menor, la urgencia y la inminencia de un peligro o perjuicio, pudiendo limitar su uso a los supuestos que exijan esa respuesta tuitiva y urgente, de tal manera que sin la concurrencia de tales requisitos o premisas no debe acudirse a la vía de dicho precepto.

53. Desde nuestro punto de vista, el retorno de las y los hijos en casos de violencia de género no puede quedar minimizado a la mera existencia de medidas de protección, porque ello no garantiza el interés superior de la persona menor ${ }^{126}$. Poner el foco únicamente en las medidas de protección para la restitución obviando la problemática vinculada a la violencia machista favorece la posición del maltratador ${ }^{127}$ cuando, de verificarse su existencia, la decisión podría estar undada en el no regreso de las víctimas ${ }^{128}$.

\section{La Orden Europea de Protección para un retorno seguro de las víctimas y de los hijos e hijas sustraídos cuando concurre violencia de género}

54. En España, cuando la sustractora fundamenta la violencia de género como causa de la huida del Estado de la residencia habitual, si no ha iniciado los trámites en el país de origen, debe denunciarla, a pesar de que en la mayoría de las ocasiones, nuestras autoridades no posean competencia para juzgar el delito de malos tratos ocasionado en el extranjero. Ante esta denuncia de malos tratos, los juzgados y tribunales españoles tienen una serie de obligaciones que se configuran como el estatuto de seguridad para la víctima y sus hijos e hijas y que, en este epígrafe, trataremos de exponer.

55. El art. 1 de la Ley 4/2015 del Estatuto de la Víctima se convierte en significativo para abordar la temática, ya que dispone que: "las disposiciones de esta Ley serán aplicables, sin perjuicio de lo dispuesto en el art. 17, a las víctimas de delitos cometidos en España o que puedan ser perseguidos en España, con independencia de su nacionalidad, de si son mayores o menores de edad o si disfrutan o no de la residencia legal". Del precepto se desprende que esta normativa se aplica a las víctimas que se hallen en España, a pesar de que los malos tratos se suscitaran en otros países de la Unión, estableciéndose una excepción frente a la territorialidad que rige la materia penal.

56. En consecuencia, la sustracción internacional de menores podría quedar resuelta por el Juzgado de Violencia sobre la Mujer ${ }^{129}$ cuando la huida del extranjero se debiese a la violencia de género y

125 R. Schuz, The Hague Child Abduction Convention: A Critical Analysis, Oxford, Hart Publishing, 2013, p. 270.

126 P. Brown and J. Meier, "Eight Letters Submitted to the U.S. State Department and the Permanent Bureau of the Hague Conference on Private International Law about a Draft Guide for Article 13(1) (b) and Related Draft Documents that were circulated for comment prior to the October 2017 meeting of the Seventh Special Commission on the 1980 Hague Child Abduction Convention at The Hague", disponible en https://law.ucdavis.edu/faculty/bruch/files/Letters-re-Hague-Convention.pd , p. 4/27.

127 A. Barnetr, "Eight Letters Submitted to the U.S. State Department and the Permanent Bureau of the Hague Conference on Private International Law about a Draft Guide for Article 13(1) (b) and Related Draft Documents that were circulated for comment prior to the October 2017 meeting of the Seventh Special Commission on the 1980 Hague Child Abduction Convention at The Hague", disponible en https://law.ucdavis.edu/faculty/bruch/files/Letters-re-Hague-Convention.pd, “Eight Letters...”, p. 19.

128 P. LuCAs, "Eight Letters Submitted to the U.S. State Department and the Permanent Bureau of the Hague Conference on Private International Law about a Draft Guide for Article 13(1) (b) and Related Draft Documents that were circulated for comment prior to the October 2017 meeting of the Seventh Special Commission on the 1980 Hague Child Abduction Convention at The Hague", disponible en https://law.ucdavis.edu/faculty/bruch/files/Letters-re-Hague-Convention.pd , p. 6/70.

129 Hay algún autor está en desacuerdo con tal posibilidad. Véase a F. J. Forcada Miranda, "El nuevo proceso español de restitución o retorno de menores en los supuestos de sustracción internacional: La decidida apuesta por la celeridad y la novedosa Circular de la Fiscalía 6/2015 (Parte II)”, Bitácora Millenium DIPr., 2016, núm. 3, en http://www.millenniumdipr.com/, 
ésta se denunciara ante la autoridad española. Sin embargo, en la actualidad, esta solución únicamente sería factible si la violencia de género se ocasiona en territorio español o, si no fuese así, se cumplieran los rigurosos presupuestos del art. 23.4 1) LOPJ ${ }^{130}$. No obstante, una vez formulada denuncia por la víctima de violencia de género y solicitadas medidas cautelares y/o limitativas de derechos en la orden de protección, el Juzgado específic ${ }^{131}$ estará obligado a admitir la denuncia y, en todo caso, resolver sobre dichas medidas por mor de lo establecido en el art. 13 de la Ley de Enjuiciamiento criminal ${ }^{132}$. Esta misma autoridad solucionará los problemas derivados de la atribución de la competencia territorial (art. 544 ter, tercero de la Ley de Enjuiciamiento Criminal ${ }^{133}$ ).

57. A pesar de que las autoridades españolas zanjen no dar curso a la investigación por falta de jurisdicción y trasladen la denuncia al tribunal extranjero donde ocurrieron los hechos delictivos conforme dispone el art. 17 de la Ley 4/2015 del Estatuto de la Víctima ${ }^{134}$, quedan obligadas a la consideración del art. 13 de la Ley de Enjuiciamiento Criminal y su remisión a los arts. 544 bis y art. 544 ter del mismo cuerpo legal. Por tanto, el juzgado puede adoptar medidas de alejamiento e incomunicación y, en su caso, orden de protección. Evidentemente, si el presunto agresor se encuentra en el extranjero, no podrá comparecer, lo que justificaría el que no se otorgue ninguna medida de alejamiento ex art. 544 bis de la Ley de Enjuiciamiento Criminal, aunque nada impide las de incomunicación, más aún si la víctima y sus hijos terminan por regresar al país donde aquél se encuentra.

58. En cuanto a las medidas referentes a los hijos o hijas, el art. 544 quinquies de la Ley de Enjuiciamiento Criminal ${ }^{135}$ dispone que caben emitirlas siempre que "exista riesgo o posible desamparo de una o un menor...". Tenemos que tener presente que la Ley integral 1/2004, tal y como ha quedado redactada por la Ley 8/2015 de protección de la infancia, en su disposición final tercera y siempre que un juzgado conozca de un asunto de violencia de género, obliga a resolver las cuestiones de la patria potestad, de custodia, de régimen de visitas y estancias o las comunicación con el otro progenitor, según los arts. 62.2 de dicha Ley integral ${ }^{136}$. En ordenamiento jurídico español, todo menor hijo o hija de mujer maltratada pasa a ser víctima directa de violencia de género a los efectos de la Ley Integral.

argumenta que tras la entrada en vigor el 23 de julio de la Ley 15/2015, si se admitiera que un Juzgado de Violencia puede conocer de este tipo de procesos, el autor considera que se rompería la lograda concentración de la competencia en España en materia de sustracción internacional, se iría contra la voluntad del legislador de 2015 y se impondría un veto no deseado a la operativa de la mediación en estos casos. Además, entre las materias civiles competencia de los juzgados de violencia parece clara la no inclusión de estos procesos en la Ley $1 / 2004$,

130 Conforme a la redacción dada por Ley Orgánica 1/2014, de 13 de marzo, de modificación de la Ley Orgánica 6/1985, de 1 de julio, del Poder Judicial, relativa a la justicia universal (BOE núm. 63, de 14 de marzo de 2014).

131 En los caso que los Juzgados de Violencia sobre la mujer no ejerzan funciones de guardia, serán competentes los Juzgados de Instrucción que realicen la guardia. La posible competencia excepcional del Juez de Instrucción de Guardia del lugar donde se presente la Orden de Protección está clarificada en la Circular de la FGE nº 6/ 1.

132 Mediante el art. 13 Ley de Enjuiciamiento criminal se obliga al juzgador, dentro de las conocidas como primeras diligencias, a proteger a los ofendidos o perjudicados por el delito, con medidas a adoptar una vez formulada denuncia y durante la tramitación del procedimiento, pudiendo acordarse a tal efecto las medidas cautelares a las que se refiere el artículo 544 bis o la orden de protección prevista en el artículo 544 ter de esta ley.

133 Que dispone: “...En caso de suscitarse dudas acerca de la competencia territorial del juez (en relación a la violencia de género), deberá iniciar y resolver el procedimiento para la adopción de la orden de protección el juez ante el que se haya solicitado ésta, sin perjuicio de remitir con posterioridad las actuaciones a aquel que resulte competente".

134 Artículo traspuesto conforme dicta el mismo precepto de la Directiva 2012/29/UE del Parlamento Europeo y del Consejo de 25 de octubre de 2012 por la que se establecen normas mínimas sobre los derechos, el apoyo y la protección de las víctimas de delitos.

135 El art. 544 quinquies fue introducido por el apartado catorce de la disposición final primera de la Ley 4/2015, de 27 de abril, del Estatuto de la víctima del delito, por tanto, es posterior a la última modificación del art. 13 de la Ley de Enjuiciamiento Criminal, que fue redactado por el artículo primero de la Ley 27/2003, de 31 de julio, reguladora de la Orden de protección de las víctimas de la violencia doméstica (BOE núm. 183, de 1 agosto de 2003).

${ }^{136}$ Que dispone que: "En todos los procedimientos relacionados con la violencia de género, el Juez competente deberá pronunciarse, en todo caso, de oficio o a instancia de las víctimas, de los hijos, de las personas que convivan con ellas o se hallen sujetas a su guarda o custodia, del Ministerio Fiscal o de la Administración de la que dependan los servicios de atención a las víctimas o su acogida, sobre la pertinencia de la adopción de las medidas cautelares y de aseguramiento contempladas en este capítulo, especialmente sobre las recogidas en los artículos 64, 65 y 66, determinando su plazo y su régimen de cumplimiento $\mathrm{y}$, si procediera, las medidas complementarias a ellas que fueran precisas". 
59. Consideramos, por tanto, que interponer denuncia por un hecho delictivo cometido en la UE, en los términos del art. 17 del Estatuto de la Víctima, exige previamente la puesta en marcha de un primer juicio de valor sobre la competencia territorial y, una vez determinada esta, se asume el procedimiento como propio o, en su caso, remitir el asunto a la autoridad extranjera competente. Posteriormente, se debe entrar en si los hechos en sí son subsumibles en tipo delictivo, porque en otro caso sería rechazado a través del oportuno sobreseimiento. Es ahí donde debe operar el art. 13 de la Ley de Enjuiciamiento Criminal y, por ende, valorar la situación de la víctima y sus hijos o hijas y la necesidad de medidas de seguridad. Al juzgador se le debe de aportar, junto con la denuncia, elementos suficientes para poder enjuiciar la imposición de dichas medidas, que son meramente cautelares y que serán revisadas por el órgano que resulte competente en la UE cuando la víctima y su prole se trasladen al extranjero. Se trataría de una especie de garantía in itínere, con una duración mínima mientras que transcurre el tiempo entre la interposición de la denuncia, la determinación de la competencia territorial y la recepción definitiva del procedimiento por el órgano que resulte competente.

60. Una vez dictadas estas medidas cautelares, atendiendo a que la víctima y sus hijos e hijas acaben regresando al Estado miembro donde se encuentra su residencia habitual, la autoridad española aconsejará a las personas protegidas que presenten su solicitud de OEP antes de salir del territorio del Estado de emisión (art. 130 de la Ley 23/2014) ${ }^{137}$. Tratándose de nuestro derecho interno, el título habilitante de una medida de protección, cuando es una medida cautelar, podría venir dado con arreglo a la legislación vigente por alguna de las siguientes resoluciones: a) un auto de medidas cautelares del art. 544 bis de la Ley de Enjuiciamiento Criminal: prohibición de residir, acudir a determinado lugar, aproximarse o comunicarse con una persona; b) una orden de protección de las reguladas en el art. 544 ter de la Ley de Enjuiciamiento Criminal; c) un auto de medidas de protección adoptadas al amparo de lo dispuesto en los arts. 62 y siguientes de la Ley integral $1 / 2004^{138}$. De todos modos, de no ser así y cuando la víctima salga del país sin el dictado de la OEP, ésta podrá formular su solicitud en el Estado de ejecución ante los órganos judiciales competentes.

61. En los procesos de restitución de los menores expuestos a la violencia de género, la solicitud de la OEP tiene por finalidad asegurar que las medidas de protección sean continuadas en el Estado donde va a regresar la víctima y su prole ${ }^{139}$, si bien se refieren únicamente a las de naturaleza penal ${ }^{140}$. En todo caso, en relación a las medidas civiles adoptadas por la autoridad española según el art. 544

137 La Directiva 2011/99/UE del Parlamento Europeo y del Consejo, de 13 de diciembre de 2011, sobre la Orden Europea de Protección ha motivado la publicación de la Ley 23/2014 de 20 de noviembre, de reconocimiento mutuo de resoluciones penales en la Unión Europea (BOE núm. 282, de 21 de noviembre de 2014) y de la Ley Orgánica 6/2014 de 29 de octubre complementaria de la Ley de reconocimiento mutuo de resoluciones penales en la Unión Europea, por las que se modifica la Ley Orgánica 6/1985, de 1 de julio, del Poder Judicial (BOE núm. 263, de 30 de octubre de 2014), modifico de nuevo el art. 87 ter de la LOPJ para incluir la letra g) en el párrafo 1 y atribuir la competencia a los Juzgados de Violencia sobre la Mujer para la emisión y la ejecución de los instrumentos de reconocimiento mutuo de resoluciones penales en la Unión Europea que les atribuya la ley, entre los que se encuentra la Orden Europea de Protección. En este sentido, hay que tener en cuenta también el Reglamento 606/2013, relativo al reconocimiento mutuo de medidas de protección en materia civil, se ha previsto como complementario a la Directiva 2011/99/UE. La existencia de dos instrumentos normativos distintos, una Directiva y un Reglamento, con mecanismos de reconocimiento distintos, aunque persiguen una misma finalidad y utilizan los mismos medios, resulta confusa. La originaria razón de desdoblar las respuestas normativas deriva de las diferentes tradiciones jurídicas que parten normas europeas (naturaleza penal; civil o administrativa).

138 Véase C. Cueto Moreno, "La orden europea de protección. Su transposición en el proyecto de ley de reconocimiento mutuo de resoluciones penales en la Unión Europeo", Revista de derecho constitucional europeo, 2014, pp. 221-260.

139 Sobre la puesta en práctica de la orden de protección europea véase FreiXes, T. y RomÁn, L. (DIRs.) (2015). La orden europea de protección..., op. cit., www.epogender.eu; NAVAS BláNQUEZ, J. J. (2017). La víctima de violencia de género en el espacio judicial. Revista Violencia sobre la Mujer, en http://www.ajfv.es/wp-content/uploads/2017/05/BOLET\%C3\%8DNVIOLENCIA-MAY-17.pdf (consultado el 2 de junio de 2018).

${ }^{140}$ El art. 5 de la Directiva, dispone: a) la prohibición de entrar en determinadas localidades lugares o zonas definidas en las que la persona protegida reside o frecuenta; b) la prohibición o regulación de cualquier tipo de contacto o por cualquier tipo de medio con la persona protegida, y c) la prohibición o reglamentación del acercamiento a la persona protegida a una distancia menor de la indicada en la medida. En todo caso, la Directiva consta de 42 considerandos, muy útiles para interpretar y poner en contexto el contenido de los siguientes 25 artículos. Vid. más ampliamente T. FreIXES y L. Román (DIRS.), La orden europea de protección.., op. cit., www.epogender.eu 
quinquies de la Ley de Enjuiciamiento Criminal, éstas tendrán que ser reconocidas mediante otros instrumentos, como es el RBr. II bis (art. 20). Este tipo de medidas avalan más seguridad en el retorno y no debe significar tener que dilatar el procedimiento de restitución, aunque nunca se debería anteponer la cuestión temporal al interés superior del o de la menor en un retorno seguro.

62. La solución que se acaba de presentar puede mejorar el bienestar y la seguridad de las víctimas ante la decisión obligada de regreso de las y de los hijos sustraídos al país de la residencia habitual, siempre que la orden de protección española como la europea se haga valer ${ }^{141}$ o sea conocida por la autoridad judicial que tenga competencia en materia de sustracción internacional de menores ${ }^{142}$.

\section{Conclusiones}

63. Los debates sociales y jurídicos abiertos sobre los supuestos de sustracción internacional de menores en los que concurra una situación de violencia de género obligan a reflexionar críticamente sobre los motivos y/o reticencias de reconocer a este tipo de casos como violencia de género. Máxime teniendo en cuenta que, desde la entrada en vigor del Convenio de Estambul, el concepto de violencia contra las mujeres abarca también la protección de sus hijas e hijos, reconociéndoles el estatuto de víctimas de la violencia machista, incluso cuando son meramente testigos de dicha violencia estructural.

64. El sistema de resolución instaurado en el CLH 1980 tiene graves inconvenientes cuando la sustracción se produce en un contexto de violencia doméstica o de género, puesto que no permite valorar adecuadamente la protección del o de la menor en este escenario. La Conferencia de La Haya asume que esta problemática no ha sido abordada con precisión, aunque reconoce que ha de ser solventada con prontitud para alcanzar soluciones que promuevan una apreciación más uniforme del motivo más invocado para rechazar el retorno de los menores, como es el art. 13.1 b) CLH 1980.

65. Respecto a los desplazamientos ilícitos de menores realizados entre Estados miembros, el principal escollo viene derivado de la restricción en la aplicación del art. 13.1 b) CLH 1980, debido a la imposición del art. 11.4 RBr. II bis. Las autoridades requeridas de los Estados miembros se ven obligadas a adoptar decisiones de retorno, incluso cuando constatan el grave riesgo de las y los hijos expuestos a la violencia de género, siempre que se adopten las medidas adecuadas para un retorno seguro. A su vez, el mecanismo de última palabra instaurado en los arts. 11.6 y $11.8 \mathrm{RBr}$. II bis no arroja luz a la compleja realidad de la violencia de género y el secuestro ilícito de la o del menor, ya que la autoridad del país de origen puede terminar obligando a su regreso, incluso cuando previamente se decidió la no restitución. Todo ello refleja la obsesión por la consecución de espacio de libertad, igualdad y seguridad jurídica en el marco de la UE, sin reparar en la vulnerabilidad de las y los menores en contextos de ataque a la mujer.

66. En estos momentos, existe un procedimiento de revisión para la aprobación de un nuevo Texto de Refundición del RBr. II bis, en el que seguimos advirtiendo la falta de implementación entre lo dispuesto en el Convenio de Estambul y las soluciones contenidas en materia de sustracción internacional de menores. Ello provoca que reaparezca en repetidas ocasiones la tensión entre la protección del interés superior de la o del menor expuesto a la violencia de género y el refuerzo de la confianza mutua en el espacio judicial civil europeo. A pesar de esa falta interconexión, existen ciertas propuestas que pueden disminuir los riesgos que conlleva el procedimiento de sustracción ilícita de menores que trae su causa en la violencia de género, aunque no son suficientes. En todo caso, en estos momentos

\footnotetext{
${ }^{141}$ La orden de protección podrá hacerse valer ante cualquier autoridad y Administración pública (art. 544 ter, apartado 5 de la Ley de Enjuiciamiento Criminal).

142 Para ello, debería consultarse el Registro Central para la Protección de las Víctimas de Violencia Doméstica, donde se inscriben las penas y medidas de seguridad impuestas en sentencia por delito; medidas cautelares y órdenes de protección acordadas en procedimientos penales en tramitación, en contra alguna de las personas a las que se refiere el artículo 173.2 de la Ley Orgánica 10/1995, de 23 de noviembre, del Código Penal.
} 
seguimos prestando atención al proceso de tramitación del Texto de Refundición para comprobar si se refuerza -con independencia de si responde o no al anhelo de una mayor profundización en el proceso de integración- la protección integral de la o del menor sustraído con motivo de la violencia de género.

67. En el ordenamiento español, aún perviven flecos legislativos que mejoren la valoración del grave riesgo de las y los menores sustraídos en situaciones de violencia de género y el procedimiento para ser retornados. Este panorama origina que, desde el punto de vista de la jurisprudencia, se genere un difícil ajuste en los casos de violencia de género acreditada y la alegación del motivo de grave riesgo del o de la menor para su devolución. Desde nuestro punto de vista, la orden de protección europea puede ayudar a la víctima y a sus hijos e hijas a realizar un retorno más seguro al país que tendrá que decidir sobre los temas de responsabilidad parental y el impacto de la violencia de género. Los instrumentos europeos de reconocimiento mutuo de decisiones penales y civiles pueden generar una mejora de la situación.

68. En definiti a, consideramos necesaria la implementación del Convenio de Estambul en los textos europeos relativos a los procesos familiares y de menores. De esta manera sería más fácil romper la automaticidad de la restitución inmediata, generando garantías más precisas para las personas menores sustraídas por violencia de género/doméstica. Por ello, quedamos a la espera de la toma de decisiones contundentes por la UE y los Estados miembros para erradicar la patología de la huida de la madre con sus hijos e hijas por temor a los malos tratos. 